\title{
Quantifying the Relationship between Leaf Nitrogen Content and Growth Dynamics and Yield of Muskmelon Grown in Plastic Greenhouse
}

\author{
Xiaofeng Yang ${ }^{1}$ \\ College of Agriculture, Hainan University, No. 58, Renmin Avenue, Haikou, \\ Hainan Province, 570228, China; and Sanya Science and Technology \\ Academy for Crop Winter Multiplication, No. 2, Hairun Road, Sanya, \\ Hainan Province, 572000, China
}

Gang Li ${ }^{1}$, Weihong Luo, and Lili Chen

College of Agriculture, Nanjing Agricultural University, No. 1, Weigang Road, Nanjing, Jiangsu Province 210095, China

Shaopeng $\mathbf{L i}^{2}$

College of Horticulture and Landscape Architecture, Hainan University, No. 58, Renmin Avenue, Haikou, Hainan Province, 570228, China

\section{Ming Cao and Xuebin Zhang}

Sanya Science and Technology Academy for Crop Winter Multiplication, No. 2, Hairun Road, Sanya, Hainan Province, 572000, China

Additional index words. muskmelon, nitrogen, leaf photosynthetic rate, leaf area index, partitioning index, model

\begin{abstract}
The aim of this study was to quantitatively investigate the impacts of nitrogen on growth dynamics and yield, so as to facilitate the optimization of nitrogen management for muskmelon crop in plastic greenhouse. For this purpose, four experiments with different levels of nitrogen treatment and planting dates on muskmelon (Cucumis melo $\mathrm{L}$. 'Nanhaimi' and 'Xizhoumi 25') were conducted in plastic greenhouse located at Sanya from Nov. 2012 to Sept. 2014. The quantitative relationship between leaf nitrogen content and growth dynamics and yield of muskmelon was determined and incorporated into a photosynthesis-driven crop growth model (SUCROS). Independent experimental data were used to validate the model. The critical leaf nitrogen content at flowering stage for muskmelon 'Nanhaimi' and 'Xizhoumi 25 ' were 19.8 and $21.0 \mathrm{mg} \cdot \mathrm{g}^{-1}$. The coefficient of determination $\left(r^{2}\right)$ and the relative root-mean-squared error (rRMSE) between the predicted and measured value of growth dynamics and yield were, respectively, 0.91 and $10.8 \%$ for leaf area index (LAI), 0.90 and $19.6 \%$ for dry weight of shoot (DWSH), 0.76 and $30.3 \%, 0.82$ and $21.1 \%$, and 0.92 and $11.9 \%$ for dry weight of leaf (DWL), stem (DWST), and fruit (DWF), 0.91 and $17.3 \%, 0.89$ and $13.9 \%, 0.86$ and $27.8 \%$, and 0.88 and $20.6 \%$ for soluble sugar content (SU), soluble protein content (PR), vitamin C content (VC), and soluble solids content (SO) of fruit, and 0.90 and $10.1 \%$ for fresh weight of fruit (FWF). The model could be used for the optimization of nitrogen management for muskmelon production in plastic greenhouse. Further calibration and test would be needed during the application of the model in wider range of conditions and muskmelon cultivars.
\end{abstract}

Muskmelon (Cucumis melo L.) is one of the most important high-value crops in protective cultivation. In China, the planting area of muskmelon was $42 \times 10^{4}$ ha with the fruit yield exceeded $1400 \times 10^{7} \mathrm{~kg}$ in 2013 .

Received for publication 18 June 2015. Accepted for publication 24 Aug. 2015 .

This work was supported by National Natural Science Foundation of China (31260492), National Science and Technology Supporting Project of China (2014BAD05B04).

${ }^{1}$ These authors contributed equally to this work.

${ }^{2}$ Corresponding author. E-mail: lisp555@126.com
Nitrogen plays an important role in crop growth and yield formation, which decides on the economic benefits (Dai et al., 2011; He et al., 2009). The excessive application of nitrogen fertilizer causes adverse environmental impacts including the accumulation of soil salt and destruction of crumb structure (Beman et al., 2005; Castellanos et al., 2013). Therefore, the optimization of greenhouse crop nitrogen management is of utmost importance to secure product quality of the muskmelon, which also plays a crucial role in reducing the environmental hazards.

Photosynthesis, LAI, and dry matter partitioning are essential for guaranteeing the crop growth, yield, and fruit quality (SU, PR, $\mathrm{VC}$, and SO) of horticultural crops. Therefore, for the optimization of crop nitrogen management, it is essential to quantify the impacts of nitrogen on crop growth processes. The existed report on the impacts of nitrogen on crop growth and yield gave the similar conclusions that the increased nitrogen application in a certain range could incline leaf chlorophyll content, the activity of nitrate reductase, the LAI and leaf photosynthetic rate, and then significantly increased dry matter production and nitrogen absorption (Cabello et al., 2009; Kirnak et al., 2005; Padilla et al., 2014; Peri et al., 2003). On the other hand, nitrogen adjusted the dry matter partitioning to leaf and other organs indirectly, which eventually affected fruit yield (Goins et al., 2004; Valdés-Gómez et al., 2014; Zvomuya and Rosen, 2002). These studies provided qualitative description of nitrogen impacts on crop growth and yield, but incapable of quantitative investigation. The simulation studies concentrated on the production system assessment and the methodologies for improving nitrogen resource use and reducing adverse environmental impact (Jamieson and Semenov, 2000; Rinaldi, 2004; Xue et al., 2007). These empirical models use various indicators to account for the crop response to nitrogen fertilizer and lack the reasonable quantitative analysis, thus, cannot well reflect the growth of crops under different nitrogen levels that limits the application and popularization of models (Asseng et al., 2000). Previous simulation studies of muskmelon were reported mainly on the simulation of growth and yield at potential production level (Baker et al., 2001; Yuan et al., 2005; Yuan et al., 2006a, 2006b), hence, cannot be directly applied for crops grown under limited nitrogen supply conditions. For the optimization of nitrogen management, a model is needed for quantitatively assessing the impacts of nitrogen on growth dynamics and yield.

The objective of this study was to develop a dynamics model to quantitatively investigate the impacts of nitrogen on growth dynamics and yield to facilitate the optimization of nitrogen management for muskmelon production in plastic greenhouse. For this purpose, four experiments with different levels of nitrogen treatment and planting dates were carried out in plastic greenhouse to collect data for model development and validation

\section{Materials and Methods}

Plant materials and nitrogen treatment design. Four experiments of different levels of nitrogen treatment and planting dates were conducted in plastic greenhouse of Sanya Science and Technology Academy for Crop Winter Multiplication $\left(18^{\circ} 15^{\prime} \mathrm{N}, 109^{\circ} 30^{\prime} \mathrm{E}\right)$ from Nov. 2012 to Sept. 2014.

The orientation of plastic greenhouse is from south to north direction. The length, span, and height were, respectively, 36, 4.6, and $3.2 \mathrm{~m}$. In each experiment, muskmelon 
seedlings with the same size were planted in soilless substrate with silver black compound film cover and irrigated by drip fertigation. The planting density was $2.2 \mathrm{plant} / \mathrm{m}^{2}$. The plot of an area of $16.5 \mathrm{~m}^{2}$ for each nitrogen treatment with three replicas was arranged in a randomized block design. To keep the same nitrogen treatment level for each experiment, cultivation substrate was made of the new mixture of coconut chaff and river sand with the ratio $2: 1$. For disinfection, $30 \mathrm{~g} \cdot \mathrm{m}^{-3}$ carbendazim was used. The $\mathrm{pH}$, available nitrogen $\left(C_{\mathrm{n}}\right)$, available phosphorus, available potassium, and bulk density of the substrate were, respectively, $6.63 \pm 0.2,12.2 \pm$ $0.2 \mathrm{mg} \cdot \mathrm{kg}^{-1}, 141 \pm 16 \mathrm{mg} \cdot \mathrm{kg}^{-1}, 416 \pm 23$ $\mathrm{mg} \cdot \mathrm{kg}^{-1}$, and $(0.8 \pm 0.1) \times 10^{6} \mathrm{mg} \cdot \mathrm{m}^{-3}$. Standard commercial crop management practices (except nitrogen concentration of the nutrient solution during nitrogen treatment period) were used for growing muskmelon crops.

Four levels of nitrogen concentration treatment (N7: 7, N10: 10, N13: 13, and $\left.\mathrm{N} 16: 16 \mathrm{mmol} \cdot \mathrm{L}^{-1}\right)$ were used in each experiment based on the Yamazaki muskmelon nutrient solution concentration. The microelement were $\mathrm{NaFe}-E D T A 30 \mathrm{mg} \cdot \mathrm{L}^{-1}, \mathrm{H}_{3} \mathrm{BO}_{3}$ $2.85 \mathrm{mg} \cdot \mathrm{L}^{-1}, \quad \mathrm{MnSO}_{4} \cdot \mathrm{H}_{2} \mathrm{O} 2.10 \mathrm{mg} \cdot \mathrm{L}^{-1}$, $\mathrm{ZnSO}_{4} \cdot 7 \mathrm{H}_{2} \mathrm{O} 0.22 \mathrm{mg} \cdot \mathrm{L}^{-1}, \mathrm{CuSO}_{4} \cdot 5 \mathrm{H}_{2} \mathrm{O} 0.08$ $\mathrm{mg} \cdot \mathrm{L}^{-1}$, and $\left(\mathrm{NH}_{4}\right)_{6} \mathrm{Mo}_{7} \mathrm{O}_{24} \cdot 4 \mathrm{H}_{2} \mathrm{O} 0.02 \mathrm{mg} \cdot \mathrm{L}^{-1}$.

From planting date to the early stage of fruit development, 0.5 times of nutrient solution with $0.5 \mathrm{~L}$ was used once a day $(0800$ $1100 \mathrm{HR}$ ) for each plant. From early stage of fruit development to last stage of fruit development, 1 times of the nutrient solution with $1.0 \mathrm{~L}$ was used twice a day (0800-1100 HR and 1500-1800 HR) for each plant. From last stage of fruit development to the harvest date (fruit ripening process), 0.5 times of nutrient solution with $0.5 \mathrm{~L}$ was used once a day (0800-1100 HR) for each plant.

Expt. 1: The planting date was 21 Nov. 2012, the flowering date was 24 Dec. 2012, and the harvest date was 4 Feb. 2013. The cultivar was Nanhaimi.

Expt. 2: The planting date was 21 Mar. 2013, the flowering date was 14 Apr. 2013, and the harvest date was 5 May 2013. The cultivar was Nanhaimi.

Expt. 3: The planting date was 13 Jan. 2014, the flowering date was $10 \mathrm{Feb} .2014$, and the harvest date was 29 Mar. 2014. The cultivars were Nanhaimi and Xizhoumi 25.

Expt. 4: The planting date was 17 July 2014, the flowering date was 10 Aug. 2014, and the harvest date was 25 Sept. 2014. The cultivars were Nanhaimi and Xizhoumi 25.

Measurements. In each experiment, the light intensity, air temperature at a height of $1.5 \mathrm{~m}$ aboveground (ZDR-24; ZEDR Inc., Hangzhou, Zhejiang, China), and substrate temperature (HE-02New; ZEDR Inc.) inside the plastic greenhouse were monitored automatically every $10 \mathrm{~s}$, and the 30-min averaged data were recorded using a datalogger (Fig. 1; only Expts. 3 and 4 were recorded for substrate temperature). The light intensity (lx) readings were converted to photosynthetic active radiation $\left(P A R, \mu \mathrm{mol} \cdot \mathrm{m}^{-2} \cdot \mathrm{s}^{-1}\right)$ by using the following approximation: $54 \mathrm{~lx}=1$ $\mu \mathrm{mol} \cdot \mathrm{m}^{-2} \cdot \mathrm{s}^{-1}$ for sunlight as recommended by Burnell et al. (2014).

To obtain the maximum leaf gross photosynthetic rate $\left(P_{\mathrm{g}, \max }, \mu \mathrm{mol} \quad \mathrm{CO}_{2} / \mathrm{m}^{2} / \mathrm{s}\right)$, a model parameter, the $P A R$-saturated net photosynthetic rate $\left(P_{\mathrm{n}, \max }, \mu \mathrm{mol} \mathrm{CO} \mathrm{CO}_{2} / \mathrm{m}^{2} / \mathrm{s}\right)$ of new fully expanded leaf (the second leaf from the top downward) at flowering stage, was measured four times (on the same leaf) with 1-h interval during 0900-1200 HR on sunny days using an open gas exchange system (LI-COR 6400; LI-COR Inc., Lincoln, NE) with standard 6- $\mathrm{cm}^{2}$ leaf chamber and red-blue LED light source (LI-640002B). Saturating $P A R$ was kept at 1500 $\mu \mathrm{mol} \cdot \mathrm{m}^{-2} \cdot \mathrm{s}^{-1}$ and three readings (1-min interval for each reading) in $P_{\mathrm{n}, \max }$ were recorded to ensure the measurement stability and precision and the average value of the three readings was used for data analysis, and then $P_{\mathrm{g}, \max }$ were calculated according to dark respiration rate $\left(R_{\mathrm{d}}=0.52 \mu \mathrm{mol} \mathrm{CO} \mathrm{CO}_{2} / \mathrm{m}^{2} / \mathrm{s}\right)$ obtained by Yuan et al. (2006b).

In each experiment, one plant per plot (three plants in total for each nitrogen treatment) was randomly selected for destructive growth dynamics measurements once every
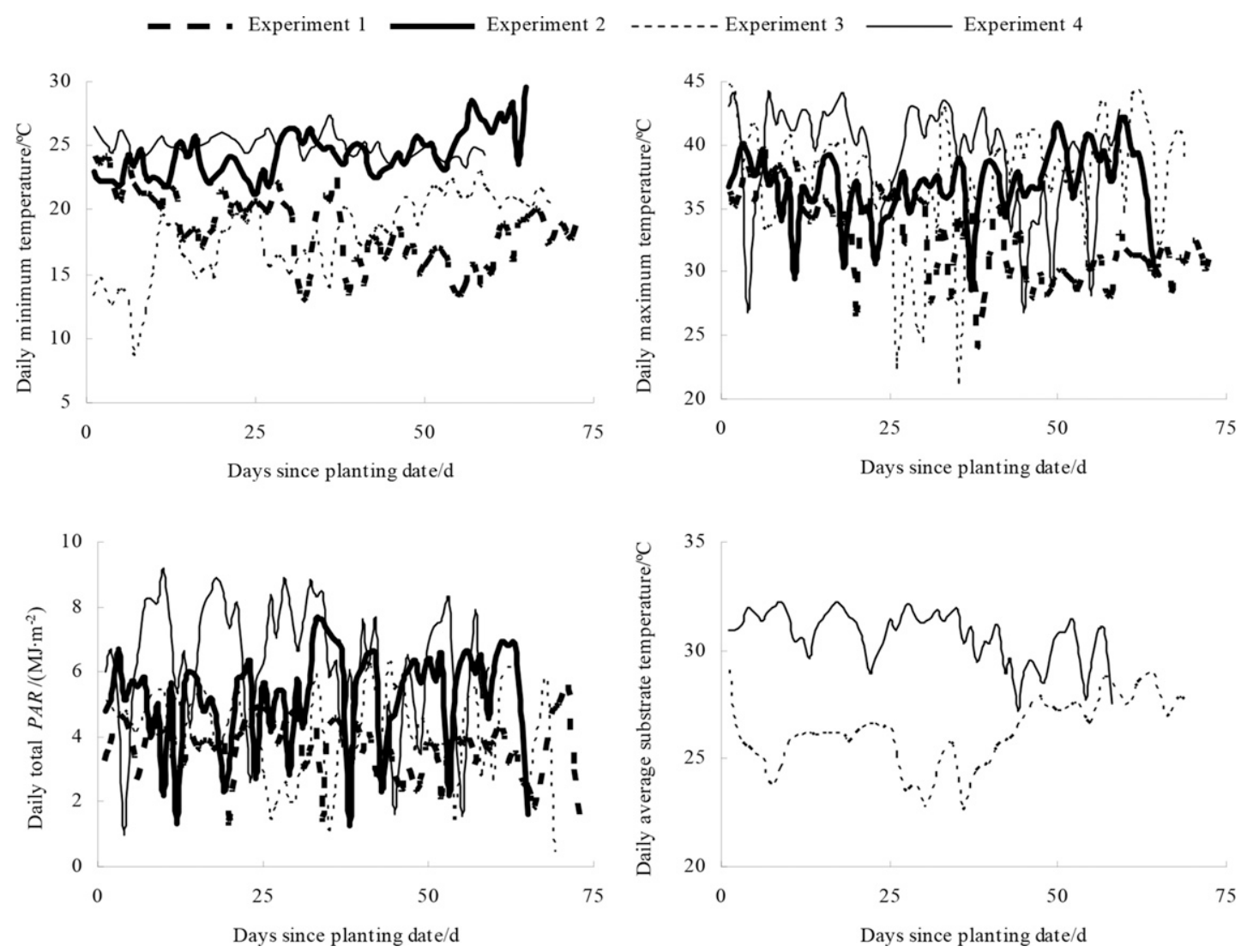

Fig. 1. Daily maximum temperature, minimum temperature, daily total photosynthetically active radiation $(P A R)$, and daily average substrate temperature since planting date in plastic greenhouse. 
$15 \mathrm{~d}$ since planting date. The measurements of leaf included the length and area of each leaf node (LI-3000A; LI-COR Inc.). The leaf length, measured from leaf tip to the point of petiole intersection along the midrib, was used to estimate leaf area and LAI. The leaf available nitrogen content was determined using the Kjeldahl method. After flowering, fruit quality traits-SU, PR, VC, and SO were determined, respectively, using the anthrone colorimetric method, the Coomassie brilliant blue G250 method, the 2, 6-dichlorindophenol titration method, and the handheld glucose meter. Partitioning of dry matter was modeled in two steps: first, between the root and the shoot, and then among organs within the shoot. Within-shoot organs included leaf, stem, and fruit, which needed measurement of their fresh weight and dry weight (drying 15 min under $105^{\circ} \mathrm{C}$, continuous drying until the weight unchanging under $75^{\circ} \mathrm{C}$ ).

Model structure. The overall model structure is shown in Fig. 2. The data of Expt. 3 were used for model development, and those of the rest three experiments were used for model validation. The inputs of the model were environmental information (air temperature, $P A R$ at a $1.5-\mathrm{m}$ height aboveground, and substrate temperature inside the plastic greenhouse), available nitrogen during the experimental season (the sum of the available nitrogen in the substrate at the planting stage and the nitrogen applied in the experimental season), and crop information (planting date and planting density). Using data of Expt. 3, the following six steps were taken to develop the model: 1) the photothermal index (PTI) (defined as the daily average normalized thermal time multiplied by the daily total $P A R$ intercepted by canopy) was calculated according to $\mathrm{Xu}$ et al. (2010) using daily total $P A R$, hourly air temperature at $1.5 \mathrm{~m}$ aboveground, and planting density; 2) the nitrogen indicator $\left(N_{1}\right.$, leaf nitrogen content at flowering stage) was calculated according to available nitrogen content during the experimental season and the average temperature of substrate; 3$)$ the leaf gross photosynthetic rate $\left(P_{\mathrm{g}}\right)$ was simulated using negative exponential equation and the impacts of $N_{1}$ on the parameter $\left(P_{\mathrm{g}, \max }\right.$, the $P A R$-saturated leaf gross photosynthetic rate) were determined by curve fitting the experimental data; 4) the LAI was determined as functions of PTI by curve fitting the experimental data and the impacts of $N_{1}$ on the parameters $\left(\mathrm{LAI}_{\max }\right.$ and $r_{\mathrm{LAI}}$, the maximum value of LAI and the increasing rate of LAI) was quantified by curve fitting the experimental data; 5) the seasonal change of partitioning index of dry matter [partitioning index of shoot, leaf, stem, and fruit (PISH, PIL, PIST and PIF, respectively)] and fruit quality traits (SU, PR, $\mathrm{VC}$, and $\mathrm{SO}$ ) were determined as functions of PTI by curve fitting the experimental data and the impacts of $N_{1}$ on partitioning index and fruit quality traits were quantified by linking
$N_{\mathrm{l}}$ to the related parameters, 6 ) the LAI, organ dry weight (DWSH, DWL, DWST, and DWF), FWF and quality (SU, PR, VC, and $\mathrm{SO})$ were estimated by integrated the simulation of leaf photosynthetic rate, LAI, seasonal changes of dry matter partitioning and fruit quality traits into the existing SUCROS (Goudriaan and Van Laar, 1994). Details of this model approach and main equations were outlined below.

Determination of the PTI. Temperature and radiation are the main climate factors affecting the growth dynamics and yield of muskmelon. The accumulated PTI (PTI $\left.{ }_{\text {sum }}\right)$ was used to describe the dynamics of growth and yield. According to $\mathrm{Xu}$ et al. (2010), the PTI was calculated as follows (Eqs. [1] and [2]):

$$
\operatorname{DPTI}(j)=\left(\frac{1}{48} \sum_{i=1}^{j} T T(i, j)\right) \times P A R_{\text {int }}(j)
$$

$$
\mathrm{PTI}_{\text {sum }}=\sum \operatorname{DPTI}(j)
$$

where $\operatorname{DPTI}(j)\left(\mathrm{MJ} \cdot \mathrm{m}^{-2} \cdot \mathrm{d}^{-1}\right)$ is the PTI on day $j, P A R_{\mathrm{int}}(j)\left(\mathrm{MJ} \cdot \mathrm{m}^{-2} \cdot \mathrm{d}^{-1}\right)$ is the daily total $P A R$ intercepted by crop canopy on day $j, \mathrm{TT}(i, j)$ is the half-hourly based normalized thermal time on day $j$, and $\mathrm{PTI}_{\text {sum }}\left(\mathrm{MJ} \cdot \mathrm{m}^{-2}\right)$ is the accumulated PTI. $P A R_{\text {int }}(j)$ and TT $(i, j)$ were calculated according to Xu et al. (2010).

Determination of nitrogen indicator. In this study, the available nitrogen during the experimental season $\left(N_{\mathrm{s}}, \mathrm{kg} \cdot \mathrm{ha}^{-1}\right)$ was used to explore the impacts of nitrogen on the growth dynamics and yield of muskmelon (Table 1), and calculated as follows (Eqs. [3]-[5]):

$$
\begin{gathered}
N_{\mathrm{s}}=N_{\mathrm{p}}+N_{\mathrm{a}} \\
N_{\mathrm{p}}=C_{\mathrm{p}} \times H \times B \times 10^{-2} \\
N_{\mathrm{a}}=C_{\mathrm{f}} \times M \times L \times \rho \times D \times P \times 10^{-2}
\end{gathered}
$$

where $N_{\mathrm{s}}\left(\mathrm{kg} \cdot \mathrm{ha}^{-1}\right)$ is the available nitrogen during the experimental season, $N_{\mathrm{p}}\left(\mathrm{kg} \cdot \mathrm{ha}^{-1}\right)$ is the available nitrogen in the substrate at the planting stage, $N_{\mathrm{a}}\left(\mathrm{kg} \cdot \mathrm{ha}^{-1}\right)$ is the nitrogen applied in the experimental season, $C_{\mathrm{p}}$ $\left(\mathrm{mg} \cdot \mathrm{kg}^{-1}\right)$ is the available nitrogen content in the substrate, $H(\mathrm{~m})$ is the depth of root, $0.3, B\left(\mathrm{~kg} \cdot \mathrm{m}^{-3}\right)$ is the bulk density, $C_{\mathrm{f}}$ $\left(\mathrm{mmol} \cdot \mathrm{L}^{-1}\right)$ is the fertilizer concentration of nutrient solution, $M\left(\mathrm{~g} \cdot \mathrm{mol}^{-1}\right)$ is the relative molecular mass, $L[\mathrm{~L} /($ plant $/ \mathrm{d})]$ is the daily used nutrient solution per plant, $\rho$ (plant $\left./ \mathrm{m}^{2}\right)$ is the planting density, $D(\mathrm{~d})$ is the number of

Fig. 2. Conceptual framework of the model developed in our study.

\begin{tabular}{|c|c|c|c|c|c|}
\hline Nitrogen treatment & & N7 & N10 & N13 & N16 \\
\hline Available nitrogen in the substrate at the planting stage $\left(\mathrm{kg} \cdot \mathrm{ha}^{-1}\right)$ & & 29.28 & 29.28 & 29.28 & 29.28 \\
\hline & $\mathrm{KNO}_{3}$ & 0 & 37.55 & 75.05 & 75.05 \\
\hline Available nitrogen during the experimental season $\left(\mathrm{kg} \cdot \mathrm{ha}^{-1}\right)$ & & 116.83 & 154.38 & 191.88 & 233.08 \\
\hline
\end{tabular}

Predicting fruit fresh weight $(F W F)$ and quality
$(S U, P R, V C$ and $S O)$

Predicting fruit fresh weight $(F W F)$
$(S U, P R, V C$ and $S O)$

$(D W S H, D W L, D W S T$ and $D W F)$

Table 1. Available nitrogen during the experimental season. 
fertilizations, $P$ is the percentage of nitrogen for the fertilizer, and $10^{-2}$ is the conversion factor from $\mathrm{mg} \cdot \mathrm{m}^{-2}$ into $\mathrm{kg} \cdot \mathrm{ha}^{-1}$.

Relationship between the leaf nitrogen content at different development stages and available nitrogen during the experimental season $\left(N_{\mathrm{s}}\right)$ is shown in Fig. 3. The leaf nitrogen content at flowering stage was the highest and the nitrogen content of this stage played an important role in later growth, yield, and fruit quality. Therefore, this research used the leaf nitrogen content at flowering stage $\left(N_{1}\right)$ to quantify the impacts of nitrogen on growth dynamics and yield of muskmelon.
The relationship between available nitrogen during the experimental season and leaf nitrogen content at flowering stage is shown in Fig. 4A and D and described as Eq. [6] by curve fitting the related data of Expt. 3.

$N_{1}=N_{1, \max } \times\left(1-\exp \left(-r_{\mathrm{Nl}} \times N_{\mathrm{s}} / N_{1, \max }\right)\right)$

where $N_{1}\left(\mathrm{mg} \cdot \mathrm{g}^{-1}\right)$ is the leaf nitrogen content at flowering stage, $N_{\mathrm{s}}(\mathrm{kg} / \mathrm{ha})$ is the available nitrogen during the experimental season, $N_{1, \max }\left(\mathrm{mg} \cdot \mathrm{g}^{-1}\right)$ is the maximum value of leaf nitrogen content at flowering stage while available nitrogen during the experimental

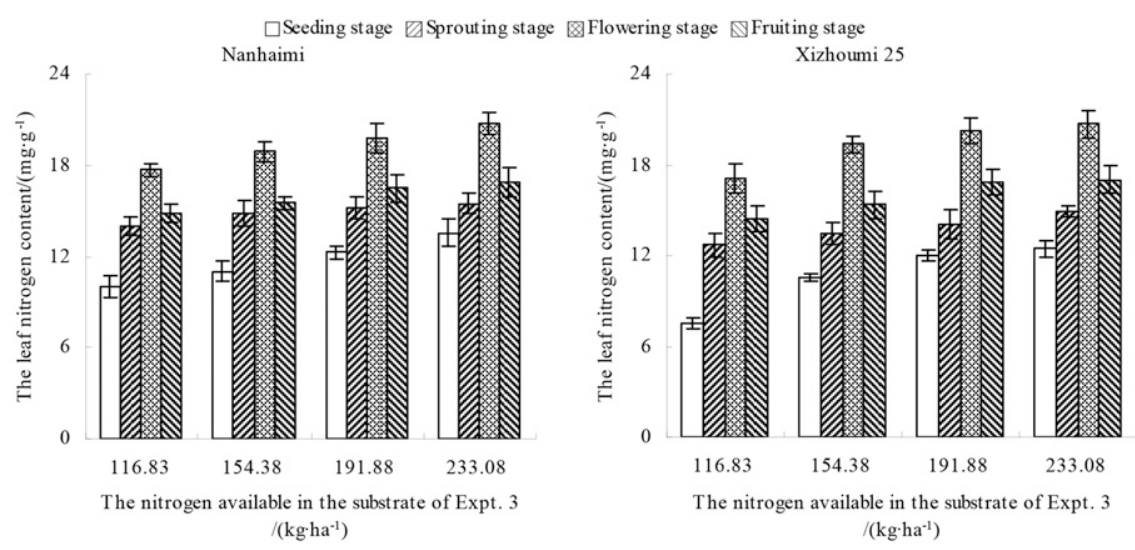

Fig. 3. Relationship between leaf nitrogen content of different development stages and available nitrogen during the experimental season of Expt. 3.

season was saturated, and $r_{\mathrm{Nl}}\left[\left(\mathrm{mg} \cdot \mathrm{g}^{-1}\right) /\right.$ $\left.\left(\mathrm{kg} \cdot \mathrm{ha}^{-1}\right)\right]$ is the increasing rate of leaf nitrogen content.

The $N_{1, \max }$ and $r_{\mathrm{Nl}}$ were affected by substrate temperature. Their relationship is shown in Fig. 4B, C, E, and F and described as Eqs. [7] and [8] by curve fitting the data of experiments.

$$
\begin{gathered}
N_{\mathrm{l}, \max }=a \times T_{\mathrm{s}}+b \\
r_{\mathrm{Nl}}=\mathrm{c} \times T_{\mathrm{s}}+d
\end{gathered}
$$

where $T_{\mathrm{s}}\left({ }^{\circ} \mathrm{C}\right)$ is the average substrate temperature during the experimental season and $a, b, c, d$ are the empirical coefficients $(0.2784,13.3978,0.0047,0.2100$ for 'Nanhaimi' and 0.6805, 3.8028, 0.0098, 0.0567 for 'Xizhoumi 25', according to experiments).

Simulation of leaf gross photosynthetic rate. The negative exponential equation (Goudriaan and Van Laar, 1994) was used to calculate leaf gross photosynthetic rate (Eq. [9]):

$$
P_{\mathrm{g}}=P_{\mathrm{g}, \text { max }} \times\left(1-\exp \left(-\varepsilon \times P A R / P_{\mathrm{g}, \max }\right)\right)
$$

where $P_{\mathrm{g}}\left(\mu \mathrm{mol} \mathrm{CO} \mathrm{CO}_{2} / \mathrm{m}^{2} / \mathrm{s}\right)$ is the leaf gross photosynthetic rate, $\varepsilon(\mu \mathrm{mol} \mathrm{CO} 2 / \mu \mathrm{mol} P A R)$ is the leaf initial light use efficiency $(0.066$ according to Yuan et al., 2006b), PAR $\left(\mu \mathrm{mol} \cdot \mathrm{m}^{2} \cdot \mathrm{s}^{-1}\right)$ is photosynthetically active radiation, $P_{\mathrm{g}, \max }\left(\mu \mathrm{mol} \mathrm{CO}_{2} / \mathrm{m}^{2} / \mathrm{s}\right)$ is the $P A R$-saturated leaf gross photosynthetic rate
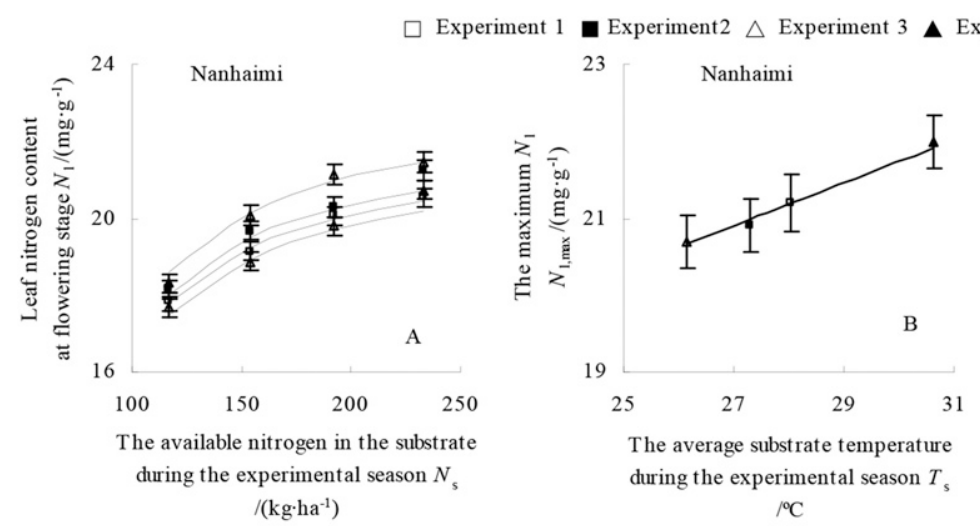

$/{ }^{\circ} \mathrm{C}$
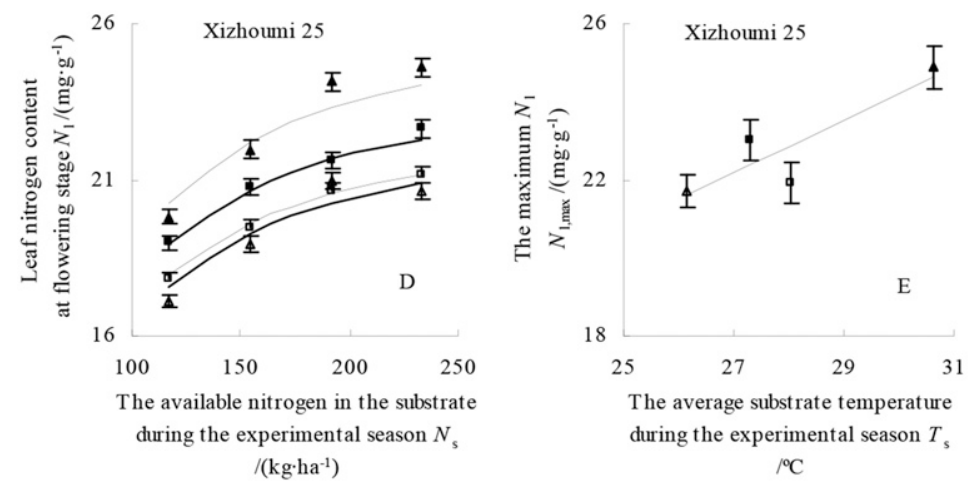
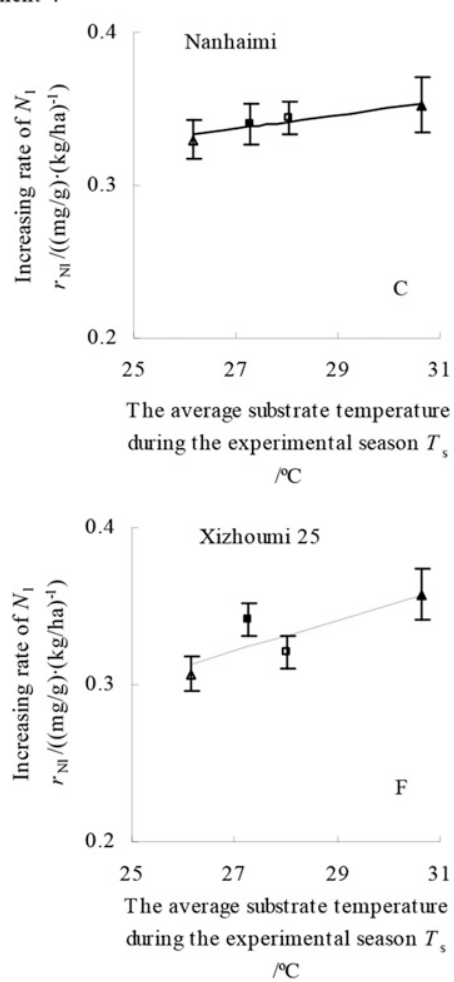

Fig. 4. Relationship between the leaf nitrogen content at flowering stage $\left(N_{\mathrm{l}}\right)$ and the available nitrogen during the experimental season $\left(N_{\mathrm{s}}\right)$, between the maximum value of leaf nitrogen content at flowering stage $\left(N_{1, \text { max }}\right)$, the increasing rate of the leaf nitrogen content $\left(r_{\mathrm{NI}}\right)$, and the average substrate temperature during the experiment season $\left(T_{\mathrm{s}}\right)$. 
at the flowering stage and determined as function of the leaf nitrogen content at flowering stage by curve fitting the data of Expt. 3 (Eq. [10], Fig. 5).

$$
\begin{aligned}
& P_{\mathrm{g}, \max } \\
& \quad=\left\{\begin{array}{cc}
P_{\mathrm{g}, \max }(0) & \left(N_{\mathrm{l}} \geq N_{\mathrm{c}}\right) \\
P_{\mathrm{g}, \text { max }}(0) \times\left(1+r_{1} \times\left(N_{\mathrm{l}}-N_{\mathrm{c}}\right)\right) & \left(N_{\mathrm{l}}<N_{\mathrm{c}}\right)
\end{array}\right.
\end{aligned}
$$

where $P_{\mathrm{g}, \max }(0)\left(\mu \mathrm{mol} \mathrm{CO} \mathrm{CO}_{2} / \mathrm{m}^{2} / \mathrm{s}\right)$ is the $P A R$ saturated leaf gross photosynthetic rate while the leaf nitrogen content at flowering stage was saturated (i.e., $N_{1} \geq N_{\mathrm{c}}$ ), $N_{1}$ ( $\mathrm{mg} \cdot \mathrm{g}^{-1}$ ) is the leaf nitrogen content at flowering stage,

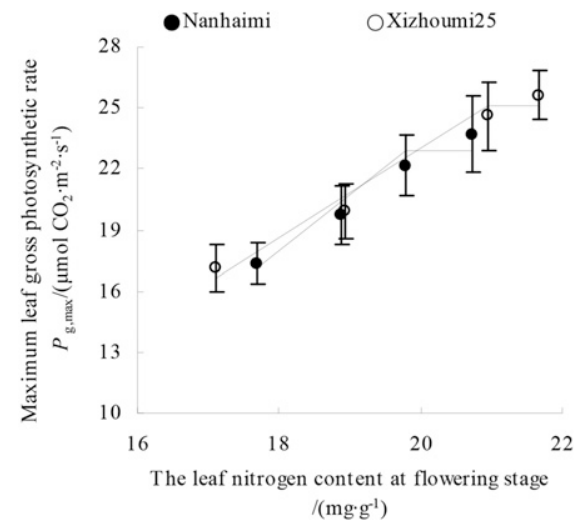

Fig. 5. Relationship between photosynthetically active radiation $(P A R)$-saturated leaf gross photosynthetic rate $\left(P_{\mathrm{g}, \max }\right)$ and the leaf nitrogen content at flowering stage $\left(N_{1}\right)$.
$N_{\mathrm{c}}$ (mg. $\mathrm{g}^{-1}$ ) is the critical value of leaf nitrogen content at flowering stage (19.8 $\mathrm{mg} \cdot \mathrm{g}^{-1}$ and $21.0 \mathrm{mg} \cdot \mathrm{g}^{-1}$ for 'Nanhaimi' and 'Xizhoumi 25', according to Expt. 3, and $r_{1}$ is the increasing rate of $P_{\mathrm{g}, \max }$ along with $N_{1}$ and the values were shown in Table 2 .

Simulation of LAI. According to the relationship between the measured leaf area and leaf length, the LAI is calculated as follows (Eqs. [11] and [12]):

$$
\begin{gathered}
\mathrm{LA}=k \times \mathrm{LL}^{2} \\
\mathrm{LAI}=\sum \mathrm{LA} \times \rho
\end{gathered}
$$

where LA $\left(\mathrm{m}^{2}\right)$ is the leaf area, LL $(\mathrm{m})$ is the leaf length, $k$ is the empirical coefficient $(0.62$ and 0.59 for 'Nanhaimi' and 'Xizhoumi 25', according to Expt. 3; data not shown), LAI $\left(\mathrm{m}^{2} / \mathrm{m}^{2}\right)$ is the LAI, and $\rho\left(\right.$ plant $\left./ \mathrm{m}^{2}\right)$ is the planting density.

The relationship between LAI and the accumulated PTI since planting date under different nitrogen supply conditions is shown in Fig. 6A and B and described as Eq. [13] by curve fitting the data of Expt. 3.

$$
\begin{aligned}
\mathrm{LAI}= & \mathrm{LAI}_{0}+\mathrm{LAI}_{\text {max }} \\
& \times\left(1-\exp \left(-r_{\mathrm{LAI}} \times \mathrm{PTI}_{\text {sum }} / \mathrm{LAI}_{\max }\right)\right)
\end{aligned}
$$

where LAI $\left(\mathrm{m}^{2} \cdot \mathrm{m}^{-2}\right)$ is the LAI, $\mathrm{LAI}_{0}$ $\left(\mathrm{m}^{2} \cdot \mathrm{m}^{-2}\right)$ is the LAI of planting date $(0.09$ and 0.08 for 'Nanhaimi' and 'Xizhoumi 25' according to Expt. 3), $\mathrm{PTI}_{\text {sum }}\left(\mathrm{MJ} \cdot \mathrm{m}^{-2}\right)$ is the accumulated PTI since planting date, $\mathrm{LAI}_{\max }$ $\left(\mathrm{m}^{2} \cdot \mathrm{m}^{-2}\right)$ is the maximum value of LAI, $r_{\mathrm{LAI}}$ $\left[\left(\mathrm{m}^{2} \cdot \mathrm{m}^{-2}\right) /\left(\mathrm{MJ} \cdot \mathrm{m}^{-2}\right)\right]$ is the increasing rate of LAI.

Parameter $\mathrm{LAI}_{\max }$ and $r_{\mathrm{LAI}}$ were determined as functions of leaf nitrogen content at flowering stage (Eqs. [14] and [15], Fig. 7A and B).

$$
\begin{aligned}
& \text { LAI }_{\text {max }} \\
& \quad=\left\{\begin{array}{cc}
\operatorname{LAI}_{\text {max }}(0) & \left(N_{\mathrm{l}} \geq N_{\mathrm{c}}\right) \\
\operatorname{LAI}_{\max }(0) \times\left(1+r_{2} \times\left(N_{\mathrm{l}}-N_{\mathrm{c}}\right)\right) & \left(N_{\mathrm{l}}<N_{\mathrm{c}}\right)
\end{array}\right.
\end{aligned}
$$

$$
r_{\mathrm{LAI}}=\left\{\begin{array}{cc}
r_{\mathrm{LAI}}(0) & \left(N_{l} \geq N_{c}\right) \\
r_{\mathrm{LAI}}(0) \times\left(1+r_{3} \times\left(N_{l}-N_{c}\right)\right) & \left(N_{l}<N_{c}\right)
\end{array}\right.
$$

where $\operatorname{LAI}_{\max }(0)$ and $r_{\mathrm{LAI}}(0)$ are the value of $\mathrm{LAI}_{\max }$ and $r_{\mathrm{LAI}}$ while the leaf nitrogen content at flowering stage was saturated (i.e., $N_{1} \geq N_{\mathrm{c}}$ ) and $r_{2}$ and $r_{3}$ are the increasing rate of LAI and $r_{\text {LAI }}$ along with $N_{1}$ and the values are shown in Table 2 .

\begin{tabular}{|c|c|c|c|c|}
\hline Parameters & Definition & Units & Nanhaimi & Xizhoumi 25 \\
\hline$\overline{P_{\mathrm{g}, \max }(0)}$ & The maximum leaf gross photosynthetic rate & $\mu \mathrm{mol} \mathrm{CO} / \mathrm{m}^{2} / \mathrm{s}$ & $22.9 \pm 1.09$ & $25.1 \pm 0.74$ \\
\hline$r_{\mathrm{LAI}}(0)$ & Increasing rate of LAI & $\left(\mathrm{m}^{2} \cdot \mathrm{m}^{-2}\right) /\left(\mathrm{MJ} \cdot \mathrm{m}^{-2}\right)$ & $0.067 \pm 0.001$ & $0.059 \pm 0.001$ \\
\hline $\mathrm{PISH}_{\mathrm{h}}(0)$ & PISH on the harvest date & & $0.987 \pm 0.010$ & $0.977 \pm 0.007$ \\
\hline $\operatorname{PIL}_{h}(0)$ & PILon the harvest date & & $0.148 \pm 0.011$ & $0.151 \pm 0.015$ \\
\hline$r_{\mathrm{PIL}}(0)$ & Increasing rate of PIL & & $0.072 \pm 0.004$ & $0.068 \pm 0.003$ \\
\hline $\mathrm{PIF}_{h}(0)$ & PIFon the harvest date & & $0.813 \pm 0.008$ & $0.825 \pm 0.025$ \\
\hline$r_{\mathrm{SU}}(0)$ & Increasing rate of $\mathrm{SU}$ & $\left(\mathrm{mg} \cdot \mathrm{g}^{-1}\right) /\left(\mathrm{MJ} \cdot \mathrm{m}^{-2}\right)$ & $0.0201 \pm 0.0002$ & $0.0204 \pm 0.0001$ \\
\hline$r_{\mathrm{PR}}(0)$ & Increasing rate of $P R$ & $(\mathrm{mg} / 100 \mathrm{~g}) /\left(\mathrm{MJ} \cdot \mathrm{m}^{-2}\right)$ & $0.0233 \pm 0.0006$ & $0.0233 \pm 0.0013$ \\
\hline$r_{\mathrm{VC}}(0)$ & Increasing rate of $\mathrm{VC}$ & $(\mathrm{mg} / 100 \mathrm{~g}) /\left(\mathrm{MJ} \cdot \mathrm{m}^{-2}\right)$ & $0.0206 \pm 0.0010$ & $0.0195 \pm 0.0006$ \\
\hline$r_{\mathrm{SO}}(0)$ & Increasing rate of $\mathrm{SO}$ & $\% /\left(\mathrm{MJ} \cdot \mathrm{m}^{-2}\right)$ & $0.0242 \pm 0.0005$ & $0.0251 \pm 0.0006$ \\
\hline$r_{1}$ & $\begin{array}{l}\text { Increasing rate of } P_{\mathrm{g}, \max } \text { along with the leaf nitrogen } \\
\text { content }\end{array}$ & $\left(\mu \mathrm{mol} \mathrm{CO} 2 / \mathrm{m}^{2} / \mathrm{s}\right) /(\mathrm{mg} / \mathrm{g})$ & $0.120 \pm 0.010$ & $0.087 \pm 0.005$ \\
\hline$r_{2}$ & $\begin{array}{l}\text { Increasing rate of } \mathrm{LAI}_{\max } \text { along with the leaf } \\
\text { nitrogen content }\end{array}$ & $\left(\mathrm{m}^{2} \cdot \mathrm{m}^{-2}\right) /\left(\mathrm{mg} \cdot \mathrm{g}^{-1}\right)$ & $0.130 \pm 0.012$ & $0.062 \pm 0.003$ \\
\hline$r_{6}$ & Increasing rate of $\mathrm{PIL}_{h}$ along with the leaf nitrogen content & & $0.225 \pm 0.021$ & $0.131 \pm 0.012$ \\
\hline$r_{7}$ & Increasing rate of $r_{\mathrm{PIL}}$ along with the leaf nitrogen content & & $-0.034 \pm 0.003$ & $-0.049 \pm 0.009$ \\
\hline$r_{8}$ & Increasing rate of $\mathrm{PIF}_{\mathrm{h}}$ along with the leaf nitrogen content & & $0.066 \pm 0.011$ & $0.045 \pm 0.005$ \\
\hline$r_{9}$ & Increasing rate of $r_{\mathrm{PIF}}$ along with the leaf nitrogen content & & $0.252 \pm 0.020$ & $0.116 \pm 0.004$ \\
\hline$r_{10}$ & Increasing rate of $\mathrm{PTI}_{\mathrm{b}}$ along with the leaf nitrogen content & $\left(\mathrm{MJ} \cdot \mathrm{m}^{-2}\right) /\left(\mathrm{mg} \cdot \mathrm{g}^{-1}\right)$ & $0.078 \pm 0.003$ & $0.084 \pm 0.010$ \\
\hline$r_{11}$ & Increasing rate of $r_{\mathrm{SU}}$ along with the leaf nitrogen content & {$\left[\left(\mathrm{mg} \cdot \mathrm{g}^{-1}\right) /\left(\mathrm{MJ} \cdot \mathrm{m}^{-2}\right)\right] /\left(\mathrm{mg} \cdot \mathrm{g}^{-1}\right)$} & $-0.047 \pm 0.006$ & $-0.028 \pm 0.006$ \\
\hline$r_{12}$ & Increasing rate of $r_{\mathrm{PR}}$ along with the leaf nitrogen content & {$\left[(\mathrm{mg} / 100 \mathrm{~g}) /\left(\mathrm{MJ} \cdot \mathrm{m}^{-2}\right)\right] /\left(\mathrm{mg} \cdot \mathrm{g}^{-1}\right)$} & $0.133 \pm 0.001$ & $0.068 \pm 0.002$ \\
\hline$r_{13}$ & Increasing rate of $r_{\mathrm{VC}}$ along with the leaf nitrogen content & {$\left[(\mathrm{mg} / 100 \mathrm{~g}) /\left(\mathrm{MJ} \cdot \mathrm{m}^{-2}\right)\right] /\left(\mathrm{mg} \cdot \mathrm{g}^{-1}\right)$} & $-0.082 \pm 0.005$ & $-0.030 \pm 0.007$ \\
\hline$r_{14}$ & Increasing rate of $r_{\mathrm{SO}}$ along with the leaf nitrogen content & {$\left[\% /\left(\mathrm{MJ} \cdot \mathrm{m}^{-2}\right)\right] /\left(\mathrm{mg} \cdot \mathrm{g}^{-1}\right)$} & $-0.047 \pm 0.003$ & $-0.034 \pm 0.005$ \\
\hline
\end{tabular}

Simulation of dry matter partitioning. The relationship between partitioning index of different organs and the accumulated PTI since planting date under different nitrogen supply conditions is shown in Fig. 6C-J and described as Eqs. [16]-[19] by curve fitting the data of Expt. 3.

Table 2. List of parameter value determined by measured data of Expt. 3 .

$\mathrm{LAI}=$ leaf area index $; \mathrm{SU}=$ soluble sugar content; $\mathrm{PR}=$ soluble protein content $; \mathrm{VC}=$ vitamin $\mathrm{C}$ content $\mathrm{SO}=$ soluble solids content $\mathrm{PISH}=$ partitioning index of shoot; PIL = partitioning index of leaf; PIF = partitioning index of fruit. 

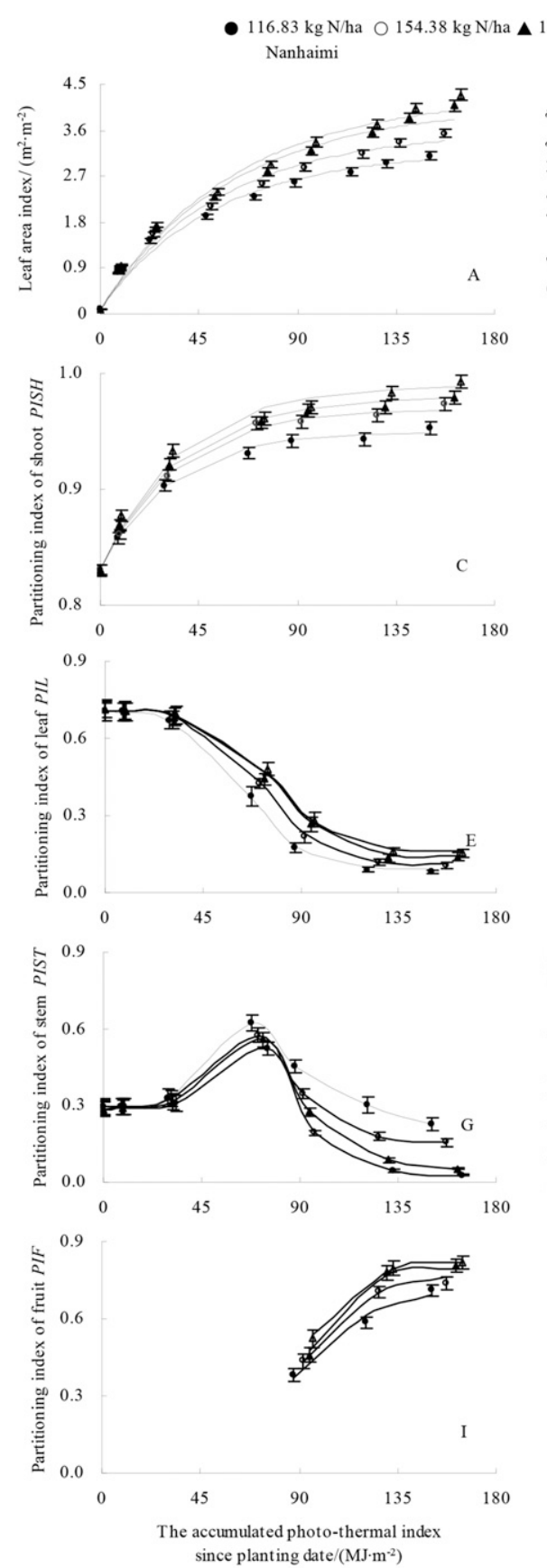

since planting date $/\left(\mathrm{MJ} \cdot \mathrm{m}^{-2}\right)$
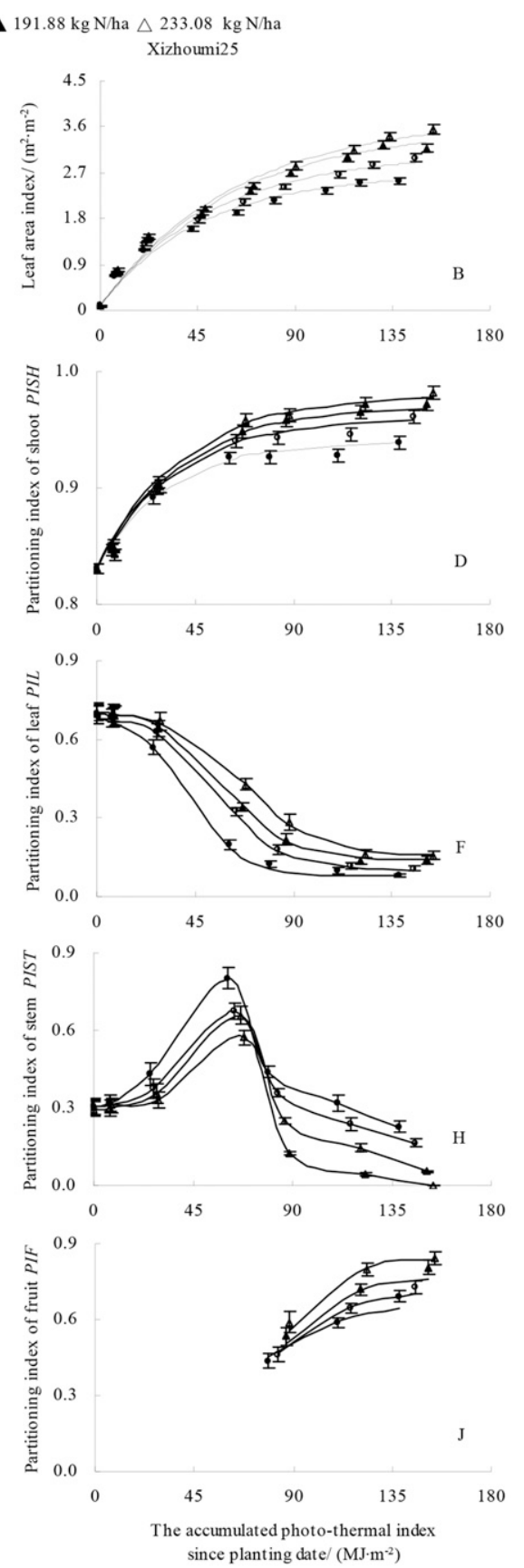

Fig. 6. Relationship between leaf area index (LAI), partitioning index of shoot (PISH), partitioning index of leaf (PIL), partitioning index of stem (PIST), partitioning index of fruit (PIF), and the accumulated photothermal index since planting date $\left(\mathrm{PTI}_{\text {sum }}\right)$ under different nitrogen supply conditions.

$$
\begin{aligned}
\mathrm{PISH}= & \mathrm{PISH}_{\mathrm{p}}+\left(\mathrm{PISH}_{\mathrm{h}}-\mathrm{PISH}_{\mathrm{p}}\right) \\
& \times\left(1-\exp \left(-r_{\mathrm{PISH}}\right.\right. \\
& \left.\left.\times \mathrm{PTI}_{\text {sum }} /\left(\mathrm{PISH}_{\mathrm{h}}-\mathrm{PISH}_{\mathrm{p}}\right)\right)\right) \\
\mathrm{PIL}= & \mathrm{PIL}_{\mathrm{p}}+\left(\mathrm{PIL}_{\mathrm{p}}-\mathrm{PIL}_{\mathrm{h}}\right) /\left(1+\exp \left(r_{\mathrm{PIL}}\right.\right. \\
& \left.\left.\times\left(\mathrm{PTI}_{\text {sum }}-\mathrm{PTI}_{\mathrm{b}}\right)\right)\right)
\end{aligned}
$$

$\mathrm{PIF}=\mathrm{PIF}_{\mathrm{h}} \times\left(1-\exp \left(-r_{\mathrm{PIF}} \times\left(\mathrm{PTI}_{\mathrm{sum}}-\mathrm{PTI}_{\mathrm{b}}\right)\right)\right)$

PIST $=1-$ PIL - PIF

where $\mathrm{PISH}_{\mathrm{p}}$ and $\mathrm{PIL}_{\mathrm{p}}$ are the partitioning index of shoot and leaf on the planting date
( 0.83 and 0.70 for 'Nanhaimi' and 'Xizhoumi 25', according to Expt. 3); $\mathrm{PISH}_{\mathrm{h}}, \mathrm{PIL}_{\mathrm{h}}$, and $\mathrm{PIF}_{\mathrm{h}}$ are the partitioning index of shoot, leaf, and fruit on the harvest date; $r_{\mathrm{PISH}}, r_{\mathrm{PIL}}$, and $r_{\mathrm{PIF}}$ are the increasing rate of partitioning index of shoot, leaf, and fruit; $\mathrm{PTI}_{\text {sum }}$ $\left(\mathrm{MJ} / \mathrm{m}^{2}\right)$ is the accumulated PTI since planting date; and $\mathrm{PTI}_{\mathrm{b}}\left(\mathrm{MJ} / \mathrm{m}^{2}\right)$ is the accumulated PTI from planting date to flowering.

The impacts of leaf nitrogen content at flowering stage on parameters $\left(\mathrm{PISH}_{\mathrm{h}}, r_{\mathrm{PISH}}\right.$, $\mathrm{PIL}_{\mathrm{h}}, r_{\mathrm{PIL}}, \mathrm{PIF}_{\mathrm{h}}, r_{\mathrm{PIF}}$, and $\mathrm{PTI}_{\mathrm{b}}$ ) are shown in Fig. 7C-I and described as Eqs. [20]-[26] by curve fitting the data of Expt. 3.

$\mathrm{PISH}_{\mathrm{h}}$

$=\left\{\begin{array}{cc}\operatorname{PISH}_{\mathrm{h}}(0) & \left(N_{\mathrm{l}} \geq N_{\mathrm{c}}\right) \\ \mathrm{PISH}_{\mathrm{h}}(0) \times\left(1+r_{4} \times\left(N_{\mathrm{l}}-N_{\mathrm{c}}\right)\right) & \left(N_{\mathrm{l}}<N_{\mathrm{c}}\right)\end{array}\right.$

$r_{\mathrm{PISH}}=\left\{\begin{array}{cc}r_{\mathrm{PISH}}(0) & \left(N_{\mathrm{l}} \geq N_{\mathrm{c}}\right) \\ r_{\mathrm{PISH}}(0) \times\left(1+r_{5} \times\left(N_{\mathrm{l}}-N_{\mathrm{c}}\right)\right) & \left(N_{\mathrm{l}}<N_{\mathrm{c}}\right)\end{array}\right.$

$\operatorname{PIL}_{\mathrm{h}}=\left\{\begin{array}{cc}\operatorname{PIL}_{\mathrm{h}}(0) & \left(N_{\mathrm{l}} \geq N_{\mathrm{c}}\right) \\ \operatorname{PIL}_{\mathrm{h}}(0) \times\left(1+r_{6} \times\left(N_{\mathrm{l}}-N_{\mathrm{c}}\right)\right) & \left(N_{\mathrm{l}}<N_{\mathrm{c}}\right)\end{array}\right.$

$r_{\mathrm{PIL}}=\left\{\begin{array}{cc}r_{\mathrm{PIL}}(0) & \left(N_{\mathrm{l}} \geq N_{\mathrm{c}}\right) \\ r_{\mathrm{PIL}}(0) \times\left(1+r_{7} \times\left(N_{\mathrm{l}}-N_{\mathrm{c}}\right)\right) & \left(N_{\mathrm{l}}<N_{\mathrm{c}}\right)\end{array}\right.$

$\mathrm{PIF}_{\mathrm{h}}=\left\{\begin{array}{cc}\operatorname{PIF}_{\mathrm{h}}(0) & \left(N_{\mathrm{l}} \geq N_{\mathrm{c}}\right) \\ \operatorname{PIF}_{\mathrm{h}}(0) \times\left(1+r_{8} \times\left(N_{\mathrm{l}}-N_{\mathrm{c}}\right)\right) & \left(N_{\mathrm{l}}<N_{\mathrm{c}}\right)\end{array}\right.$

$r_{\mathrm{PIF}}=\left\{\begin{array}{cc}r_{\mathrm{PIF}}(0) & \left(N_{\mathrm{l}} \geq N_{\mathrm{c}}\right) \\ r_{\mathrm{PIF}}(0) \times\left(1+r_{9} \times\left(N_{\mathrm{l}}-N_{\mathrm{c}}\right)\right) & \left(N_{\mathrm{l}}<N_{\mathrm{c}}\right)\end{array}\right.$

$\operatorname{PTI}_{\mathrm{b}}=\left\{\begin{array}{cc}\operatorname{PTI}_{\mathrm{b}}(0) & \left(N_{\mathrm{l}} \geq N_{\mathrm{c}}\right) \\ \operatorname{PTI}_{\mathrm{b}}(0) \times\left(1+r_{10} \times\left(N_{\mathrm{l}}-N_{\mathrm{c}}\right)\right) & \left(N_{\mathrm{l}}<N_{\mathrm{c}}\right)\end{array}\right.$

where $\operatorname{PISH}_{\mathrm{h}}(0), r_{\mathrm{PISH}}(0), \mathrm{PIL}_{\mathrm{h}}(0), r_{\mathrm{PIL}}(0)$, $\operatorname{PIF}_{h}(0), r_{\mathrm{PIF}}(0)$, and $\operatorname{PTI}_{\mathrm{b}}(0)$ are the values of $\mathrm{PISH}_{\mathrm{h}}, r_{\mathrm{PISH}}, \mathrm{PIL}_{\mathrm{h}}, r_{\mathrm{PIL}}, \mathrm{PIF}_{\mathrm{h}}, r_{\mathrm{PIF}}$, and $\mathrm{PTI}_{\mathrm{b}}$ while the leaf nitrogen content at flowering stage was saturated (i.e., $N_{1} \geq N_{\mathrm{c}}$ ) and $r_{4}-r_{10}$ are the increasing rate of these parameters along with the leaf nitrogen content at flowering stage and the values are shown in Table 2.

Simulation of fruit quality traits. The relationship between fruit quality traits and the accumulated PTI since planting date under different nitrogen supply conditions is shown in Fig. 8 and described as Eqs. [27][30] by curve fitting the data of Expt. 3 .

$$
\mathrm{SU}=\mathrm{SU}_{0} \times \exp \left(r_{\mathrm{SU}} \times\left(\mathrm{PTI}_{\text {sum }}-\mathrm{PTI}_{\mathrm{b}}\right)\right)
$$

$$
\mathrm{PR}=\mathrm{PR}_{0} \times \exp \left(r_{\mathrm{PR}} \times\left(\mathrm{PTI}_{\text {sum }}-\mathrm{PTI}_{\mathrm{b}}\right)\right)
$$

$$
\mathrm{VC}=\mathrm{VC}_{0} \times \exp \left(r_{\mathrm{VC}} \times\left(\mathrm{PTI}_{\text {sum }}-\mathrm{PTI}_{\mathrm{b}}\right)\right)
$$

$$
\mathrm{SO}=\mathrm{SO}_{0} \times \exp \left(r_{\mathrm{SO}} \times\left(\mathrm{PTI}_{\text {sum }}-\mathrm{PTI}_{\mathrm{b}}\right)\right)
$$

where $\mathrm{SU}_{0}, \mathrm{PR}_{0}, \mathrm{VC}_{0}$, and $\mathrm{SO}_{0}$ were the initial content of $\mathrm{SU}, \mathrm{PR}, \mathrm{VC}$, and $\mathrm{SO}$ $\left(10 \mathrm{mg} \cdot \mathrm{g}^{-1}, 8 \mathrm{mg} / 100 \mathrm{~g}, 1 \mathrm{mg} / 100 \mathrm{~g}\right.$, and $1 \%$, the same value for 'Nanhaimi' and 'Xizhoumi 25', according to Expt. 3), 

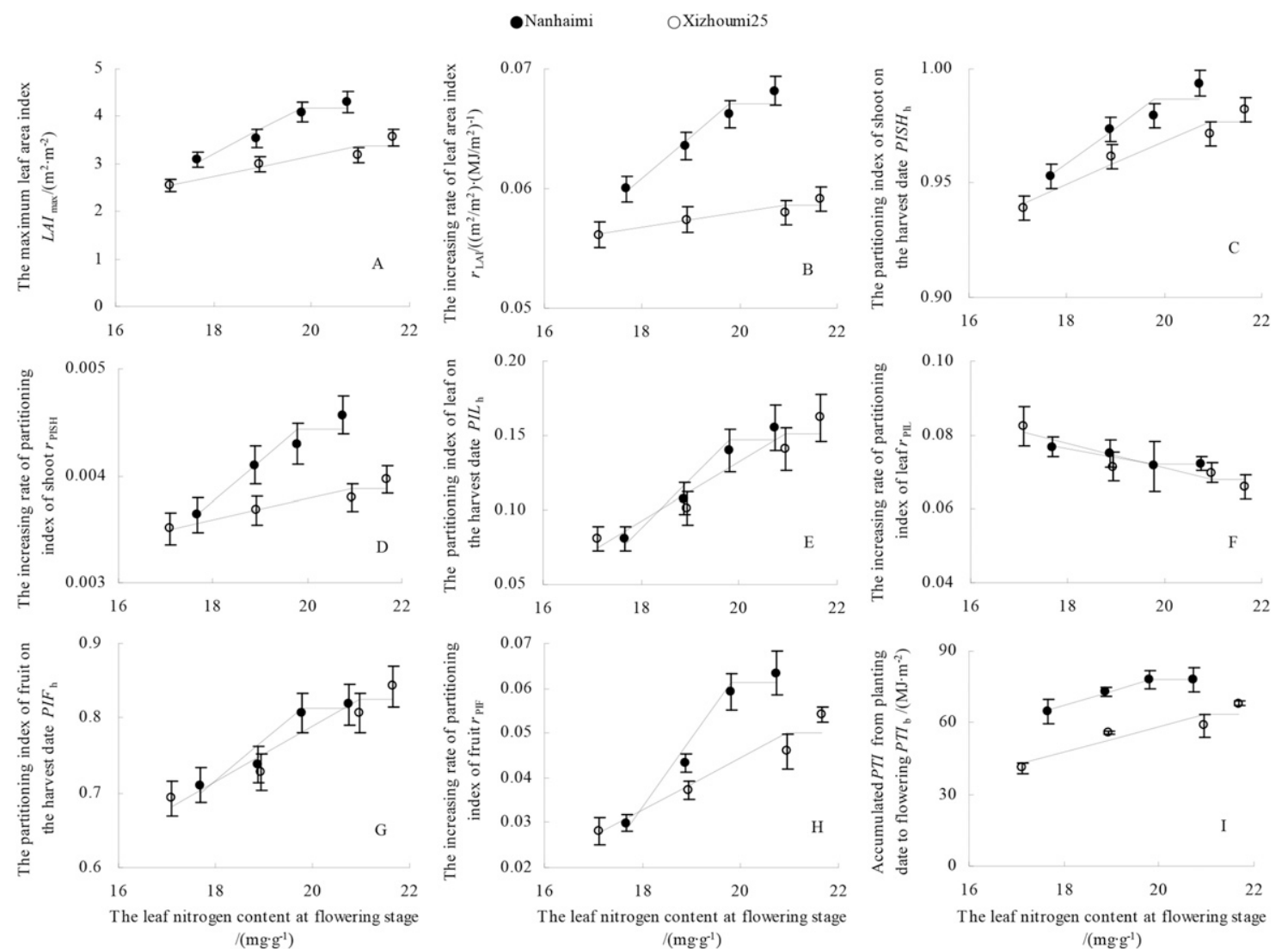

Fig. 7. Relationship between the maximum value of leaf area index $\left(\mathrm{LAI}_{\max }\right)$, the increasing rate of LAI $\left(r_{\mathrm{LAI}}\right)$, the partitioning index of shoot on the harvest date $\left(\mathrm{PISH}_{\mathrm{h}}\right)$, the increasing rate of partitioning index of shoot $\left(r_{\mathrm{PISH}}\right)$, the partitioning index of leaf on the harvest date $\left(\mathrm{PIL}_{\mathrm{h}}\right)$, the increasing rate of partitioning index of leaf $\left(r_{\mathrm{PIL}}\right)$, the partitioning index of fruit on the harvest date $\left(\mathrm{PIF}_{\mathrm{h}}\right)$, the increasing rate of partitioning index of fruit $\left(r_{\mathrm{PIF}}\right)$, accumulated PTI from planting date to flowering $\left(\mathrm{PTI}_{\mathrm{b}}\right)$, and the leaf nitrogen content at flowering stage $\left(N_{1}\right)$.

$\mathrm{PTI}_{\text {sum }}\left(\mathrm{MJ} \cdot \mathrm{m}^{-2}\right)$ was the accumulated PTI since planting date, and $\mathrm{PTI}_{\mathrm{b}}\left(\mathrm{MJ} \cdot \mathrm{m}^{-2}\right)$ was the accumulated PTI from planting date to flowering.

The impacts of leaf nitrogen content at flowering stage on parameters $\left(r_{\mathrm{SU}}, r_{\mathrm{PR}}, r_{\mathrm{VC}}\right.$, and $\left.r_{\mathrm{SO}}\right)$ are shown in Fig. 9 and described as Eqs. [31]-[34] by curve fitting the data of Expt. 3.

$r_{\mathrm{SU}}=\left\{\begin{array}{cc}r_{\mathrm{SU}}(0) & \left(N_{\mathrm{l}} \geq N_{\mathrm{c}}\right) \\ r_{\mathrm{SU}}(0) \times\left(1+r_{11} \times\left(N_{\mathrm{l}}-N_{\mathrm{c}}\right)\right. & \left(N_{\mathrm{l}}<N_{\mathrm{c}}\right)\end{array}\right.$

$r_{\mathrm{PR}}=\left\{\begin{array}{cc}r_{\mathrm{PR}}(0) & \left(N_{\mathrm{l}} \geq N_{\mathrm{c}}\right) \\ r_{\mathrm{PR}}(0) \times\left(1+r_{12} \times\left(N_{\mathrm{l}}-N_{\mathrm{c}}\right)\right. & \left(N_{\mathrm{l}}<N_{\mathrm{c}}\right)\end{array}\right.$

$r_{\mathrm{VC}}=\left\{\begin{array}{cc}r_{\mathrm{VC}}(0) & \left(N_{\mathrm{l}} \geq N_{\mathrm{c}}\right) \\ r_{\mathrm{VC}}(0) \times\left(1+r_{13} \times\left(N_{\mathrm{l}}-N_{\mathrm{c}}\right)\right. & \left(N_{\mathrm{l}}<N_{\mathrm{c}}\right)\end{array}\right.$

$r_{S O}=\left\{\begin{array}{cc}r_{\mathrm{SO}}(0) & \left(N_{l} \geq N_{c}\right) \\ r_{S O}(0) \times\left(1+r_{14} \times\left(N_{l}-N_{c}\right)\right. & \left(N_{l}<N_{c}\right)\end{array}\right.$

where $r_{\mathrm{SU}}(0), r_{\mathrm{PR}}(0), r_{\mathrm{VC}}(0)$, and $r_{\mathrm{SO}}(0)$ are the values of $r_{\mathrm{SU}}, r_{\mathrm{PR}}, r_{\mathrm{VC}}$, and $r_{\mathrm{SO}}$ while the leaf nitrogen content at flowering stage was saturated (i.e., $N_{1} \geq N_{\mathrm{c}}$ ) and $r_{11}-r_{14}$ are the increasing rate of these parameters along with the leaf nitrogen content at flowering stage and the values are shown in Table 2.

Predicting dry weight of organ and fruit quality. According to Eqs. [1]-[34], a model of plastic greenhouse muskmelon was developed by integrated the simulation of LAI, seasonal changes of dry matter partitioning and fruit quality traits into the existing SUCROS, which could be used to predict the impacts of nitrogen on dry matter production and fruit quality. DWSH,DWL, DWST, and DWF were estimated (Eqs. [35]-[38]).

$$
\begin{gathered}
\text { DWSH }=\text { BIOMASS } \times \text { PISH } \\
\text { DWL }=\text { DWS } \times \text { PIL } \\
\text { DWST }=\text { DWS } \times \text { PIST } \\
\text { DWF }=\text { DWS }- \text { DWL }- \text { DWST }
\end{gathered}
$$

Predicting the fruit yield. The yield of fruiting vegetables was mainly dependent on fresh weight of individual fruit at harvest. The relationship between dry weight and FWF is shown in Fig. 10 and described as Eq. [39] by curve fitting the data of Expt. 3.

$$
\mathrm{FWF}=\mathrm{DWF} \times \mathrm{g}
$$

where DWF (g/plant) is the dry weight of fruit, and $g$ is the empirical coefficient (11.45 and 12.10 for 'Nanhaimi' and 'Xizhoumi 25', according to Expt. 3.

Methods for model validation. The coefficient of determination of linear regression $\left(r^{2}\right)$ and the relative root-mean-squared error (rRMSE) between the predicted and measured values were used for model validation. The rRMSE was calculated as the RMSE divided by the means of measured values and was described as follows (Eqs. [40] and [41]):

$$
\begin{gathered}
r^{2}=\frac{\left(\sum(x-\bar{x})(y-\bar{y})\right)^{2}}{\sum(x-\bar{x})^{2} \sum(y-\bar{y})^{2}} \\
\text { rRMSE }=\frac{1}{\bar{x}} \sqrt{\frac{\sum_{i=1}^{n}(x-y)^{2}}{n}}
\end{gathered}
$$

where $x$ is the measured value, $y$ is the predicted value, $\bar{x}$ is the average of measured value, $\bar{y}$ is the average of predicted value, and $n$ is the numbers of sample.

\section{Results}

As shown in Figs. 5 and 7, the relationship between leaf nitrogen content at flowering stage $\left(N_{1}\right)$ and maximum LAI (LAI $\left.\mathrm{Lax}_{\max }\right)$, increasing rate of LAI at flowering stage $\left(r_{\mathrm{LAI}}\right)$, the partitioning index of shoot on the harvest 

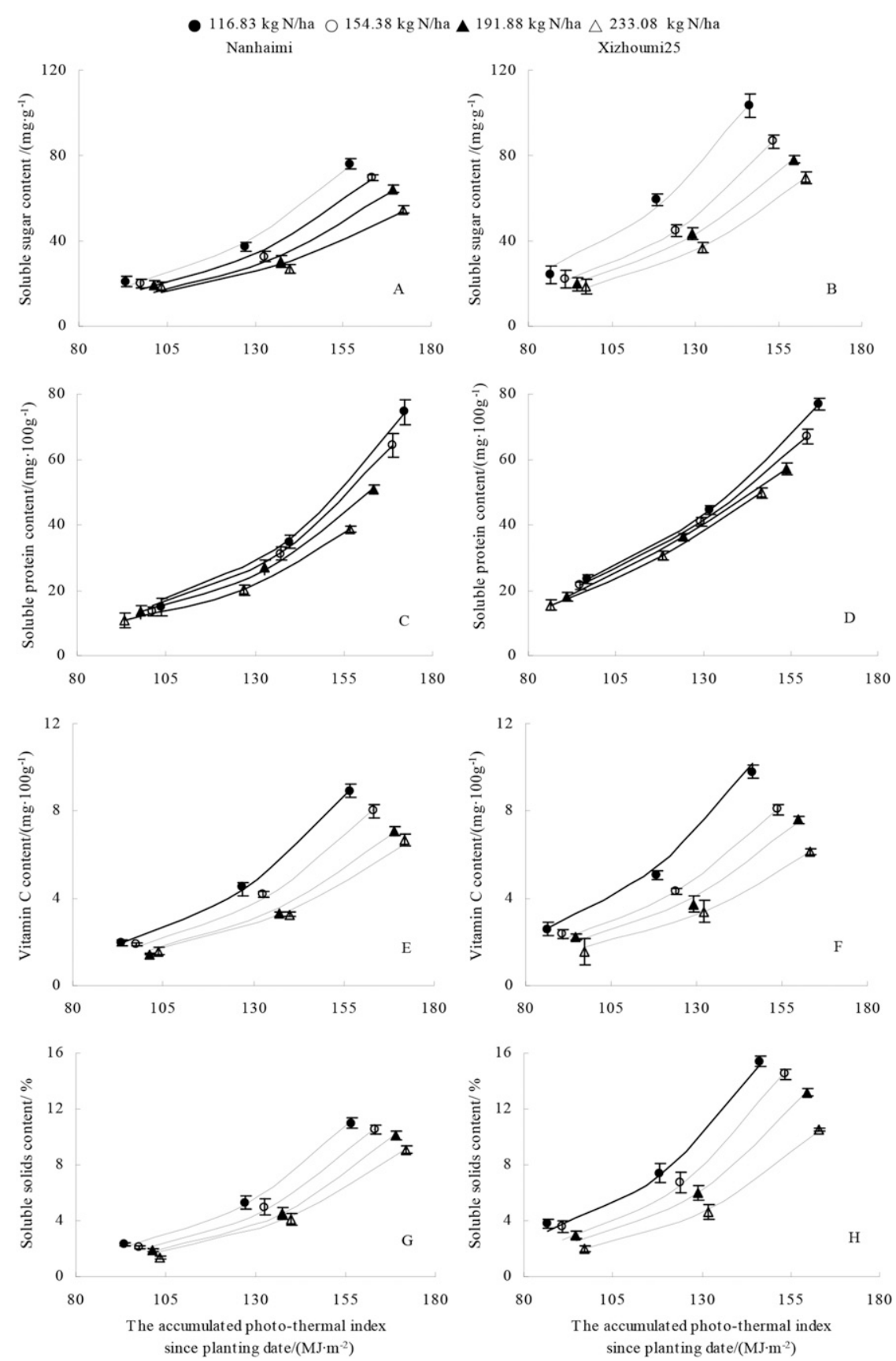

Fig. 8. Relationship between soluble sugar content (SU), soluble protein content (PR), vitamin C content (VC) and soluble solids content (SO) and the accumulated photothermal index since planting date $\left(\mathrm{PTI}_{\text {sum }}\right)$ under different nitrogen supply conditions.

date $\left(\mathrm{PISH}_{\mathrm{h}}\right)$, the increasing rate of partitioning index of shoot $\left(r_{\mathrm{PISH}}\right)$, the partitioning index of leaf on the harvest date $\left(\mathrm{PIL}_{h}\right)$, the increasing rate of partitioning index of leaf $\left(r_{\mathrm{PIL}}\right)$, the partitioning index of fruit on the harvest date $\left(\mathrm{PIF}_{\mathrm{h}}\right)$, and the increasing rate of partitioning index of fruit $\left(r_{\mathrm{PIF}}\right)$ were increasing linearly along with the leaf nitrogen content at flowering stage. But, these parameters as well as the quality and FWF (Figs. 9 and 10) would not increase when the leaf nitrogen content at the flowering stage increased to 19.8 and $21.0 \mathrm{mg} \cdot \mathrm{g}^{-1}$ for 'Nanhaimi' and 'Xizhoumi 25'. Therefore, 19.8 and $21.0 \mathrm{mg} \cdot \mathrm{g}^{-1}$ were determined as the critical leaf nitrogen content and could be used as indicator of nitrogen optimal management for muskmelon production. Corresponding to the critical value of leaf nitrogen content at flowering stage, the available nitrogen in the substrate of Expt. 1-4 for the two cultivars were, respectively, 169 , 178,196 , and $145 \mathrm{~kg} \cdot \mathrm{ha}^{-1}$ for 'Nanhaimi' and 173, 193, 247, and $132 \mathrm{~kg} \cdot \mathrm{ha}^{-1}$ for 'Xizhoumi 25'.

Independent experimental data (Expts. 1, 2 , and 4) were used to validate the model according to the Eq. [1]-[39], and the results are shown in Fig. 11. The $r^{2}$ between the predicted and measured value of LAI, DWSH, DWL, DWST, DWF, SU, PR, VC, $\mathrm{SO}$, and FWF are, respectively, 0.91, 0.90,
$0.76,0.82,0.92,0.91,0.89,0.86,0.88$, and 0.90 . The rRMSE between the predicted and measured value are, respectively, $10.8 \%$, $19.6 \%, \quad 30.3 \%, \quad 21.1 \%, \quad 11.9 \%, \quad 17.2 \%$, $13.9 \%, 27.8 \%, 20.6 \%$, and $10.1 \%$. Therefore, our research gave satisfactory predictions of growth dynamics and yield of muskmelon under different levels of nitrogen treatment.

\section{Discussion}

Temperature and PAR are the main climate factors affecting the growth dynamics and yield of crop (Justus and Kubota, 2010; Ngouajio and Ernest, 2005). It has demonstrated that only using temperature as an input parameter [growing degree days (GDD)-based model] that could not accurately describe crop growth process because temperature did not synchronize with PAR (Xu et al., 2010). Although climate of plastic greenhouse were different for the four experiments, the PTI used in our study that integrated effects of $P A R$ and temperature were used to quantitatively investigate the impacts of nitrogen on growth dynamics and yield and the results showed that it gave satisfactory predictions. This further verified the reliability of the PTI (Dai et al., 2011; Xu et al., 2010). Impacts of nitrogen on LAI can be estimated by using DWL and specific leaf area (SLA), which need destructive measurements and is strongly influenced by environmental factors and crop developmental stage (Goudriaan and Van Laar, 1994). Small error in predicting SLA values can result in unacceptable error for simulating LAI and crop biomass (Xu et al., 2010; Yin et al., 2000). Impacts of nitrogen on leaf photosynthetic rate are usually quantified using a mechanistic biochemical model (FvCB model; Farquhar, von Caemmerer and Berry, 1980). It can be used to estimate photosynthetic parameters in relation to the nitrogen conditions of plants and therefore, are useful for understanding how nitrogen affects crop growth (Yin et al., 2009). However, the huge set of data and parameters as inputs limits the practical use. In our study, although empirical, variables and parameters have clear biological meanings and are easily obtained for the simulation of LAI and leaf photosynthesis. Like the similar empirical approaches used for dry matter partitioning predictions (Connor and Fereres, 1999; Wubs et al., 2012), the empirical seasonal change of dry matter partitioning index was used to describe the dynamics of dry matter partitioning among organs.

The climate control is limited in a lowinvestment plastic greenhouse. To obtain the same yield and quality in different planting dates, we can keep the same leaf nitrogen content at flowering stage by changing the available nitrogen during the experimental season. The value was similar to the former studies that showed that the available nitrogen in the substrate was within 116-232 $\mathrm{kg} \cdot \mathrm{ha}^{-1}$ (Shafeek et al., 2015; Xu et al., 2005). It needed different supply of nitrogen 

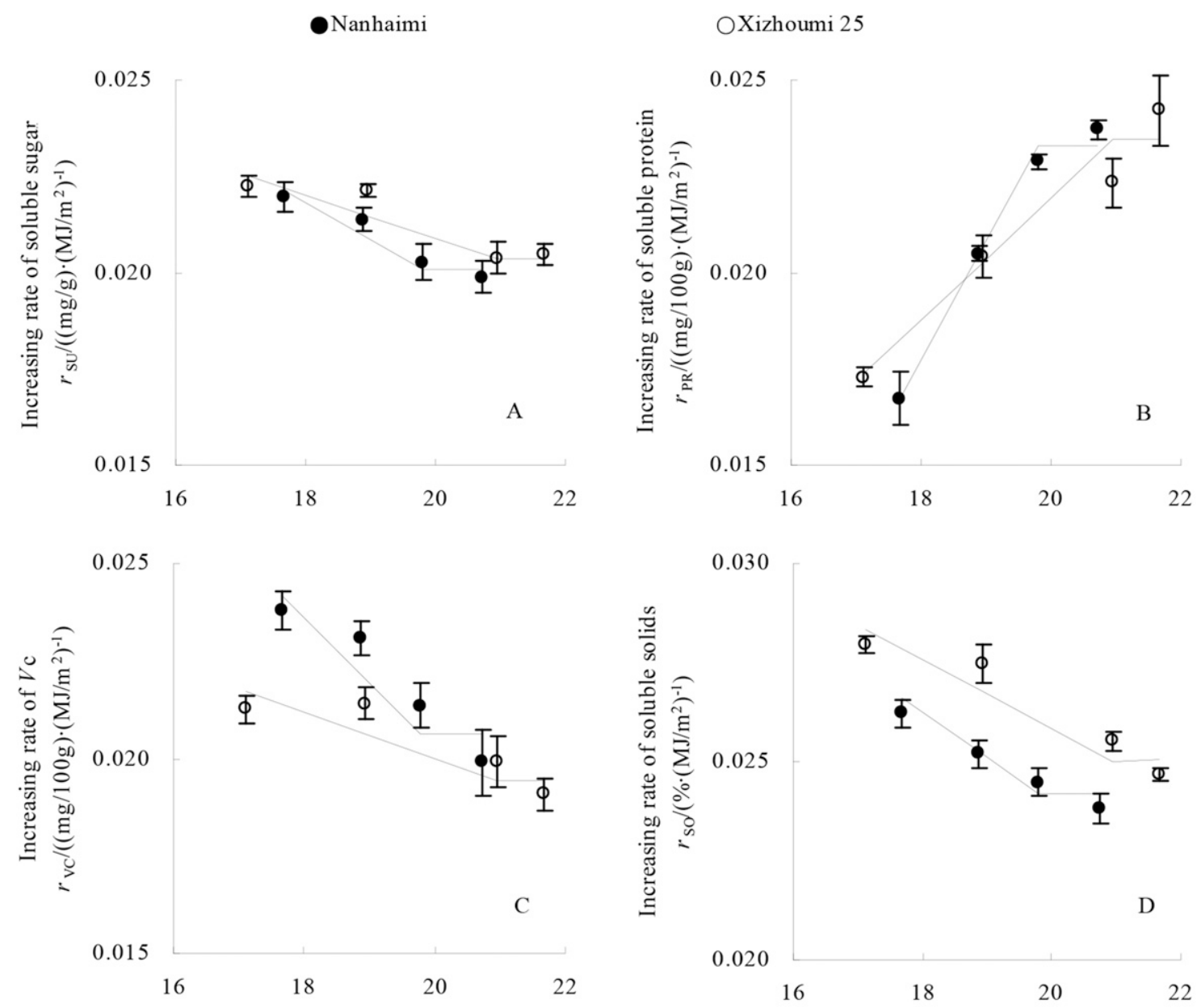

The leaf nitrogen content at flowering stage $/\left(\mathrm{mg}^{-1}\right)$

The leaf nitrogen content at flowering stage $/\left(\mathrm{mg}^{-1} \mathrm{~g}^{-1}\right)$

Fig. 9. Relationship between the increasing rate of soluble sugar $\left(r_{\mathrm{SU}}\right)$, the increasing rate of soluble protein $\left(r_{\mathrm{PR}}\right)$, the increasing rate of vitamin $\mathrm{C}\left(r_{\mathrm{VC}}\right)$, the increasing rate of soluble solids $\left(r_{\mathrm{SO}}\right)$, and the leaf nitrogen content at flowering stage $\left(N_{1}\right)$.

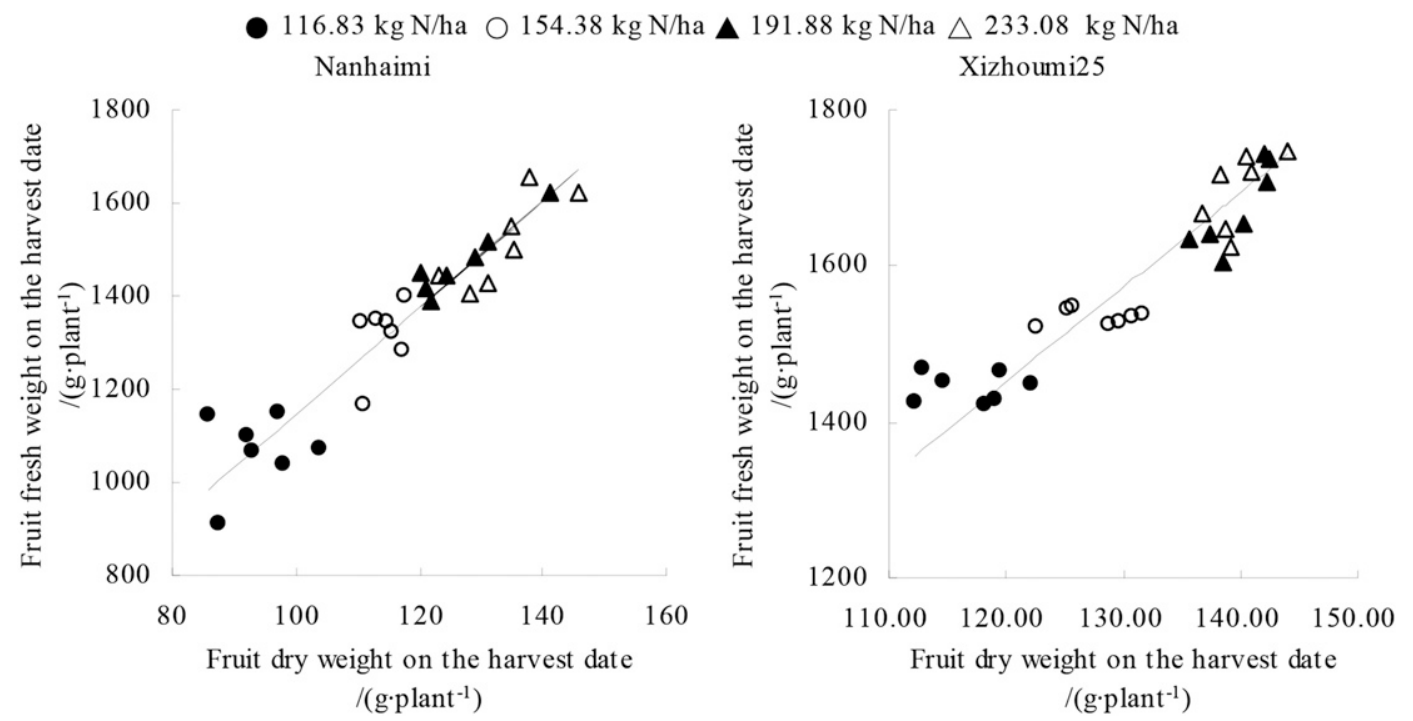

Fig. 10. Relationship between fresh weight and dry weight of muskmelon fruit.

in the substrate at different planting dates. This can be attributed to the fact that the climates of the plastic greenhouse were different for the four experiments that caused the difference of substrate temperature, and then affected the nitrogen absorption, metabolism, and transport in plant (Chmelíková and Hejcman, 2014; Kim et al., 2002; Liang et al., 2015; Roohi and Mohammadi, 2002). Therefore, estimating the supply of nitrogen in the substrate based on leaf nitrogen content was feasible for different planting dates and 

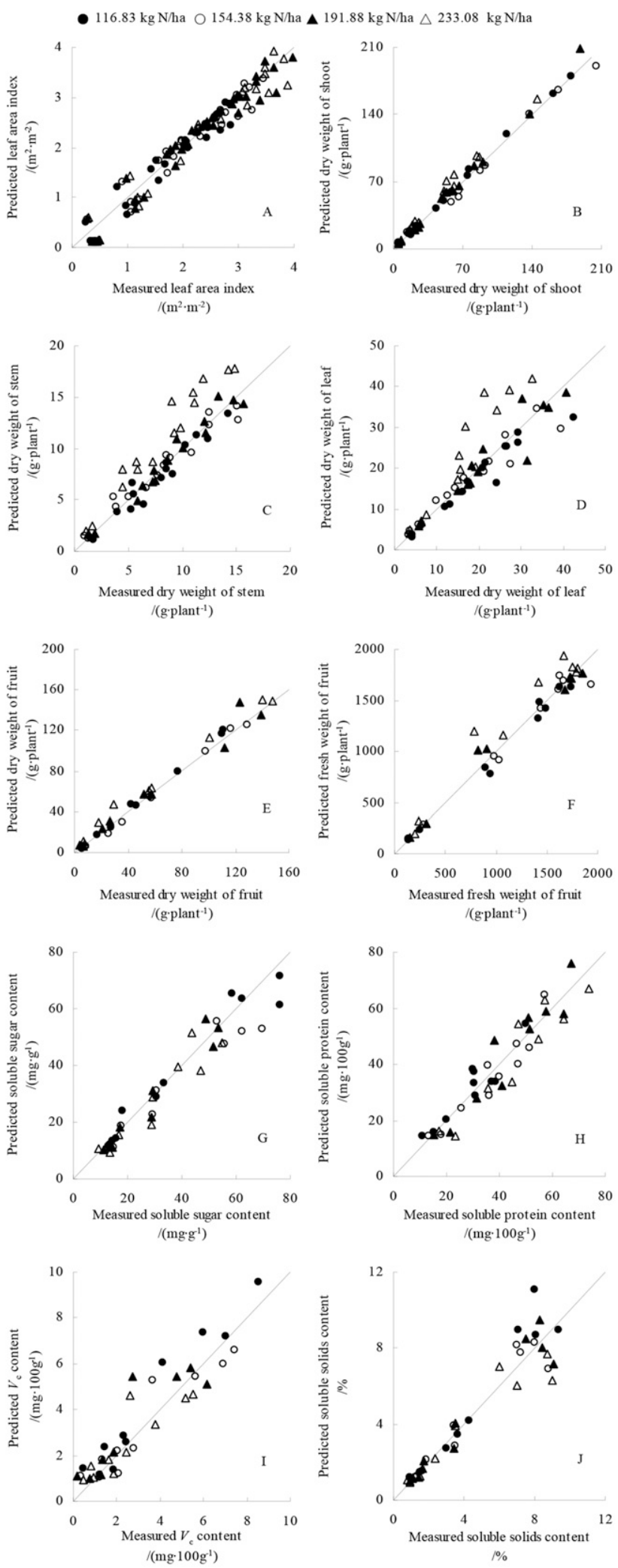

Fig. 11. Comparison between the predicted and measured leaf area index (LAI), dry weight of shoot (DWSH), dry weight of leaf (DWL), dry weight of stem (DWST), dry weight of fruit (DWF), fresh weight of fruit (FWF), soluble sugar content (SU), soluble protein content (PR), vitamin C (VC), and soluble solids content (SO).

substrate types, and helpful to ensure the yield and quality of muskmelon and improve the use efficiency of nitrogen fertilizer. Further study should focus on the ratio between different nitrogen forms in the substrate due to its effect on muskmelon growth and yield (Hassanshahian et al., 2014; Liu et al., 2014; Park and Seo, 2012).

\section{Conclusion}

In this study, a model that the accumulated PTI as a growth indicator and leaf nitrogen content at flowering stage as nitrogen indicator was developed to quantify the impacts of nitrogen on growth dynamics (leaf photosynthetic rate, LAI, dry matter partitioning and fruit quality) and yield under different levels of nitrogen treatment. Using the planting date, available nitrogen during the experimental season, the light intensity, the air temperature, and the substrate temperature as inputs, the model can give good predictions of LAI, DWSH, dry weight of organs (DWL, DWST, and DWF), FWF and quality (SU, $\mathrm{PR}, \mathrm{VC}$, and SO) of muskmelon. It can provide optimization and standardization of nitrogen management for muskmelon. Further model calibration and test would be needed when the model is applied to wider range of conditions and muskmelon cultivars.

\section{Literature Cited}

Asseng, S., H. van Keulen, and W. Stol. 2000 Performance and application of the APSIM $\mathrm{N}$-wheat model in the Netherlands. Eur. J. Agron. 12:37-54.

Baker, J.T., D.I. Leskovar, V.R. Reddy, and F.J. Dainello. 2001. A simple phenological model of muskmelon development. Ann. Bot. (Lond.) 87:615-621.

Beman, B.M., K.R. Arrigo, and P.A. Matson. 2005. Agricultural runoff fuels large phytoplankton blooms in vulnerable areas of the ocean. Nature 434:211-214.

Burnell, O.W., B.D. Russell, A.D. Irving, and S.D. Connell. 2014. Seagrass response to $\mathrm{CO}_{2}$ contingent on epiphytic algae: Indirect effects can overwhelm direct effects. Oecologia 176:871882.

Cabello, M.J., M.T. Castellanos, F. Romojaro, C. Martínez-Madrid, and F. Ribas. 2009. Yield and quality of melon grown under different irrigation and nitrogen rates. Agr. Water Mgt. 96:866-874.

Castellanos, M.T., A.M. Tarquis, F. Ribas, M.J. Cabello, A. Arce, and M.C. Cartagena. 2013. Nitrogen fertigation: An integrated agronomic and environmental study. Agr. Water Mgt. 120:46-55.

Chmelíková, L. and M. Hejcman. 2014. Effect of nitrogen, phosphorus and potassium availability on emergence, nodulation and growth of Trifolium medium L. in alkaline soil. Plant Biol. 16:717-725.

Connor, D.J. and E. Fereres. 1999. A dynamics model of crop growth and partitioning of biomass. Field Crops Res. 63:139-157.

Dai, J.F., S.S. Liu, W.R. Zhang, R. Xu, W.H. Luo, S.F. Zhang, X.Y. Yin, L. Han, and W.P. Chen. 2011. Quantifying the effects of nitrogen on fruit growth and yield of cucumber crop in greenhouse. Sci. Hort. 130:551-561.

Farquhar, G.D., S. von Caemmerer, and J.A. Berry. 1980. A biochemical model of photosynthetic $\mathrm{CO}_{2}$ assimilation in leaves of $\mathrm{C} 3$ species. Planta 149:78-90.

Goins, G.D., N.C. Yorio, and R.M. Wheeler. 2004. Influence of nitrogen nutrition management on biomass partitioning and nitrogen use efficiency indices in hydroponically grown potato. J. Amer. Soc. Hort. Sci. 129:134-140.

Goudriaan, J. and H.H. Van Laar. 1994. Modelling potential crop growth processes: Textbook with 
exercises. Current issues in production ecology, vol. 2. Kluwer Academic Publishers, Dordrecht, The Netherlands.

Hassanshahian, O., J. Javanmardi, and M.J. Behroozbeh. 2014. Effects of various rates and concentrations of $\mathrm{N}-\mathrm{P}-\mathrm{K}$ on growth ' $\mathrm{Rio}$ Grande' tomato seedling. Intl. J. Adv. Biol. Biomed. Res. 2:579-585.

He, F.F., R.F. Jiang, Q. Chen, F.S. Zhang, and F. Su. 2009. Nitrous oxide emissions from an intensively managed greenhouse vegetable cropping system in Northern China. Environ. Pollut. 157:1666-1672.

Jamieson, P.D. and M.A. Semenov. 2000. Modeling nitrogen uptake and redistribution in wheat. Field Crops Res. 68:21-29.

Justus, I. and C. Kubota. 2010. Effects of low temperature storage on growth and transplant quality of non-grafted and grafted cantaloupetype muskmelon seedlings. Sci. Hort. 125: 47-54.

Kim, T.H., Y.T. Chun, K.Y. Kim, and S.J. Chung. 2002. Root zone temperature effects on nitrate assimilation and xylem transport in hydroponically grown cucumber plants. Acta Hort. 588:59-62.

Kirnak, H., D. Higgs, C. Kaya, and I. Tas. 2005. Effects of irrigation and nitrogen rates on growth, yield, and quality of muskmelon in Semiarid regions. J. Plant Nutr. 28:621-638.

Liang, B., L.Y. Kang, T. Ren, J.L. Li, Q. Chen, and J.G. Wang. 2015. The impact of exogenous $\mathrm{N}$ supply on soluble organic nitrogen dynamics and nitrogen balance in a greenhouse vegetable system. J. Environ. Mgt. 154:351-357.

Liu, N., L. Zhang, X.X. Meng, A. Neelam, J.H. Yang, and M.F. Zhang. 2014. Effect of nitrate/ ammonium ratios on growth, root morphology and nutrient elements uptake of watermelon (Citrullus Lanatus) seedlings. J. Plant Nutr. 37:1859-1872.

Ngouajio, M. and J. Ernest. 2005. Changes in the physical, optical, and thermal properties of polyethylene mulches during double cropping. HortScience 40:94-97.
Padilla, F.M., M.T. Peña-Fleitas, M. Gallardo, and R.B. Thompson. 2014. Evaluation of optical sensor measurements of canopy reflectance and of leaf flavonols and chlorophyll contents to assess crop nitrogen status of muskmelon. Eur. J. Agron. 58:39-52.

Park, Y.H. and B.S. Seo. 2012. Changes in growth and quality of melon (Cucumis melo L.) and in soil nitrogen forms due to organic fertilizer application. Korean J. Soil Sci. Fert. 45:10091016.

Peri, P.L., D.J. Moot, and D.L. McNeil. 2003. A canopy photosynthesis model to predict the dry matter production of cocksfoot pastures under varying temperature, nitrogen and water regimes. Grass Forage Sci. 58:416-430.

Rinaldi, M. 2004. Water availability at sowing and nitrogen management of durum water: A seasonal analysis with the CERES-Wheat model. Field Crops Res. 89:27-37.

Roohi, V. and J. Mohammadi. 2002. Seasonal changes of mineral nutrients in leaves of two iranian almond cultivars. Acta Hort. 591:315319.

Shafeek, M.R., A.M. Shaheen, E.H.A. El-Samad, F.A. Rizk, and F.S.A. El-Al. 2015. Response of growth, yield and fruit quality of cantaloupe plants (Cucumis melo L.) to organic and mineral fertilization. Middle East J. Applied. Sci. 5:76-82.

Valdés-Gómez, H., C. Gary, N. Brisson, and F. Matus. 2014. Modelling indeterminate development, dry matter partitioning and the effect of nitrogen supply in tomato with the generic STICS crop-soil model. Sci. Hort. 175:44-56.

Wubs, A.M., Y.T. Ma, E. Heuvelink, L. Hemerik, and L.F.M. Marcelis. 2012. Model selection for nondestructive quantification of fruit growth in pepper. J. Amer. Soc. Hort. Sci. 137:71-79.

Xu, R., J. Dai, W. Luo, X. Yin, Y. Li, X. Tai, L. Han, Y. Chen, L. Lin, G. Li, C. Zou, W. Du, and M. Diao. 2010. A photothermal model of leaf area index for greenhouse crops. Agr. For. Meteorol. 150:541-552.

Xu, R.Y., Z.L. Bie, and D.F. Huang. 2005. Effects of different nitrogen forms on the dry matter accumulation and leaf nitrogen metabolism of muskmelon [in Chinese with English abstract]. Transactions of the Chinese Society of Agricultural Engineering 21:147-150.

Xue, X.P., J.G. Wang, Z.W. Wang, W.Q. Guo, and Z.G. Zhou. 2007. Determination of a critical dilution curve for nitrogen concentration in cotton. J. Plant Nutr. Soil Sci. 170:811-817.

Yin, X., A.H.C.M. Schapendonk, M.J. Kropff, M. van Oijen, and P.S. Bindraban. 2000. A generic equation for nitrogen-limited leaf area index and its application in crop growth models for predicting leaf senescence. Ann. Bot. (Lond.) 85:579-585.

Yin, X., P.C. Struik, P. Romero, J. Harbinson, J.B. Evers, P.E.L. van der Putten, and J. Vos. 2009. Using combined measurements of gas exchange and chlorophyll fluorescence to estimate parameters of a biochemical $\mathrm{C}_{3}$ photosynthesis model: A critical appraisal and a new integrated approach applied to leaves in a wheat (Triticum aestivum) canopy. Plant Cell Environ. 32:448-464.

Yuan, C.M., W.H. Luo, S.F. Zhang, J.F. Dai, and L. Jin. 2005. Simulation of the development of greenhouse muskmelon [in Chinese with English abstract]. Acta Hort. Sinica 32:262267.

Yuan, C.M., W.H. Luo, S.F. Zhang, L. Jin, J.H. Ni, Y.S. Chen, J.F. Dai, C.X. Bu, and G. Xu. 2006a. Simulation of leaf area and photosynthetic production of greenhouse muskmelon [in Chinese with English abstract]. J. of Nanjing Agricultural University 29:7-12.

Yuan, C.M., W.H. Luo, X. Tai, S.F. Zhang, L. Jin, Y.S. Chen, C.X. Bu, and G. Xu. 2006b. Simulation of dry matter partitioning, yield formation and fruit harvest date of greenhouse muskmelon [in Chinese with English abstract]. Scientia Agricultura Sinica 39:353-360.

Zvomuya, F. and C.J. Rosen. 2002. Biomass partitioning and nitrogen use efficiency of 'Superior' potato following genetic transformation for resistance to colorado potato beetle. J. Amer. Soc. Hort. Sci. 127:703-709. 